\title{
Long term in situ measurements of hygrothermal conditions at critical points in four cases of internally insulated historic solid masonry walls
}

Hansen, Tessa Kvist; Bjarløv, Søren Peter; Peuhkuri, Ruut Hannele; Harrestrup, Maria

Published in:

Energy and Buildings

Link to article, DOI:

10.1016/j.enbuild.2018.05.001

Publication date:

2018

Document Version

Peer reviewed version

Link back to DTU Orbit

Citation (APA):

Hansen, T. K., Bjarløv, S. P., Peuhkuri, R. H., \& Harrestrup, M. (2018). Long term in situ measurements of hygrothermal conditions at critical points in four cases of internally insulated historic solid masonry walls. Energy and Buildings, 172, 235-248. https://doi.org/10.1016/j.enbuild.2018.05.001

\section{General rights}

Copyright and moral rights for the publications made accessible in the public portal are retained by the authors and/or other copyright owners and it is a condition of accessing publications that users recognise and abide by the legal requirements associated with these rights.

- Users may download and print one copy of any publication from the public portal for the purpose of private study or research.

- You may not further distribute the material or use it for any profit-making activity or commercial gain

- You may freely distribute the URL identifying the publication in the public portal 


\section{Accepted Manuscript}

Long term in situ measurements of hygrothermal conditions at critical points in four cases of internally insulated historic solid masonry walls

Tessa Kvist Hansen , Søren Peter Bjarløv ,

Ruut Hannele Peuhkuri , Maria Harrestrup

PII:

S0378-7788(18)30042-2

DOI:

10.1016/j.enbuild.2018.05.001

Reference: $\quad$ ENB 8542

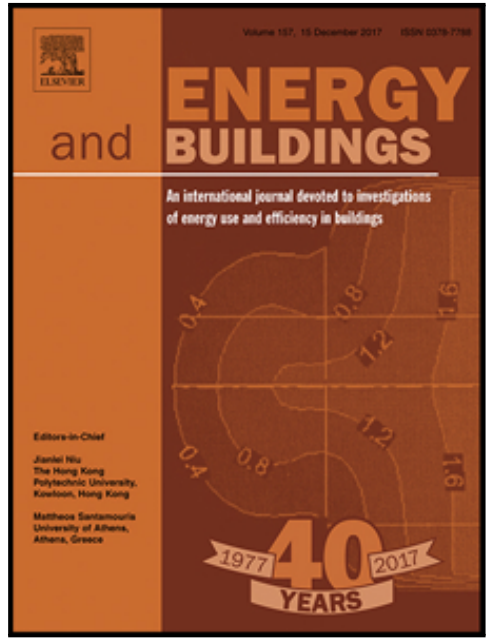

To appear in:

Energy \& Buildings

Received date: $\quad 5$ January 2018

Revised date: $\quad 4$ April 2018

Accepted date: 1 May 2018

Please cite this article as: Tessa Kvist Hansen, Søren Peter Bjarløv, Ruut Hannele Peuhkuri , Maria Harrestrup, Long term in situ measurements of hygrothermal conditions at critical points in four cases of internally insulated historic solid masonry walls, Energy \& Buildings (2018), doi: 10.1016/j.enbuild.2018.05.001

This is a PDF file of an unedited manuscript that has been accepted for publication. As a service to our customers we are providing this early version of the manuscript. The manuscript will undergo copyediting, typesetting, and review of the resulting proof before it is published in its final form. Please note that during the production process errors may be discovered which could affect the content, and all legal disclaimers that apply to the journal pertain. 


\section{Highlights}

- In situ measurements of four cases of internal insulation in Denmark are studied

- Hygrothermal performance at wall-insulation interfaces and behind beams are studied

- Measurements are analyzed with simulations and damage models

- Long term performance depends on several parameters

- All cases of internal insulation should be individually analyzed 


\title{
Long term in situ measurements of hygrothermal conditions at critical points in four cases of internally insulated historic solid masonry walls
}

\author{
Tessa Kvist Hansen ${ }^{\mathrm{a}^{*}}$, Søren Peter Bjarløv ${ }^{\mathrm{a}}$, Ruut Hannele Peuhkuri ${ }^{\mathrm{b}}$, Maria Harrestrup ${ }^{\mathrm{c}}$ \\ ${ }^{a}$ Technical University of Denmark, Department of Civil Engineering, Brovej 118, 2800 Kongens Lyngby, Denmark, \\ tekhan@byg.dtu.dk, spb@byg.dtu.dk \\ ${ }^{\mathrm{b}}$ Aalborg University, Danish Building Research Institute, A. C. Meyers Vænge 15, 2450 Copenhagen SV, Denmark, \\ rup@sbi.aau.dk
}

${ }^{c}$ Ekolab, Vestergade 48H, 2. tv, 8000 Aarhus C,, Denmark, maria.harrestrup@gmail.com

*Corresponding author. E-mail: tekhan@byg.dtu.dk, postal address: Brovej 118, 2800 Kongens Lyngby, Denmark

\begin{abstract}
In heritage buildings with solid masonry walls, where external insulation is not an option, insulating internally is an alternative way to improve indoor climate and reduce energy consumption and heat loss through external walls. This study presents results from hygrothermal measurements performed in four different buildings in Denmark where internal insulation has been installed. The buildings are all heritage buildings from 1877-1932 and of solid masonry walls. The insulated façades differ in orientation, surface treatments, location, and insulation system. The insulation materials used are phenolic foam and polyurethane (PUR) foam, with calcium silicate channels in a grid of 40X40mm. Measurement results and hygrothermal assessments indicate that a vapour barrier does not contribute positively to the performance of the system and the more vapour open, the better performance on solid masonry. However, the performance is highly dependent on other parameters like insulation thickness and surface treatment, and above all: the external hygrothermal loads. Therefore, before the application of internal insulation, every case should be carefully assessed in order to find the most suitable solution with regards to both thermal and hygrothermal performance.
\end{abstract}

\section{Keywords}

Internal insulation, in situ measurements, hygrothermal conditions, mould index 


\section{Introduction}

As society's urge for reduction of energy consumption is on the rise, so is the need for energy retrofitting measures to be implemented in the existing building stock. The European building stock itself accounts for $40 \%$ of European energy consumption [1]. Also, more than 40\% of European residential buildings were built prior to 1960 [2], thus being prior to any attention being given to energy consumption, including heat loss through external walls in cold and temperate climates. Thermal insulation is a natural measure in order to reduce the heat loss through the building envelope. Thermal insulation does not only reduce the energy demand for heating, but also provides a better indoor environment in regards to thermal comfort, utilization of indoor space, and indoor air quality [3]. External insulation is usually the moisture safest and most efficient method for reduction of heat transfer through the external walls, as it provides the existing construction with protection from the external environment and eliminates thermal bridges [4][5][6][7][8][9]. This is however not possible in many historic buildings, as the façades are either preservation worthy, or of too much cultural and aesthetic value, to change the exterior aesthetics. Therefore, internal insulation is introduced in these cases. Internal insulation however introduces several risks to the existing construction, as the hygrothermal conditions in the original construction are changed. As a result, the risk of interstitial condensation is increased [10][11][12], and the drying potential inward is reduced as the permeability is reduced by the insulation [11][13][14]. The increased risks of high moisture in the wall, inevitably leads to an increased risk of mould growth [15], and decay of the existing wood embedded in the structure. Furthermore, as a result of reduced temperature and drying potential of the existing wall, the risk of frost damage to the surface is also increased [9][10][15][14]. Internal insulation should thus not be installed without considerations to the building physics aspects. It might not be possible to achieve the desired U-value, or the desired heat loss reductions, but given the risks involved, it is far more feasible in the long run, to implement a moisture safe solution.

There are several types of insulation marketed for internal insulation [11], including capillary active and hydrophilic insulation materials [8][10][16][17], and traditional hydrophobic insulation materials including a vapour barrier. Internal insulation systems on the market can be separated into three groups based on their basic properties; 1) capillary active and vapour open, 2) vapour open and 3) vapour tight systems. Capillary active systems have the advantage of a high moisture buffering capacity, yielding the possibility of redistributing absorbed moisture for evaporation [18]. The capillary active systems are also vapour open. Vapour open systems allow transport of water vapour in the construction, but the risk of interstitial condensation increases as moist indoor air reaches the cold external wall. A vapour open 
system can be combined with a smart vapour retarder, whose vapour resistance varies depending on the relative humidity [19]. A high vapour resistance in cool periods would prevent interstitial condensation, and a reduced vapour diffusion resistance can allow drying of the wall. Vapour tight systems completely inhibit moisture transfer through the insulation, preventing vapour from diffusing through the insulation and condensing on the external wall. All these systems naturally have pitfalls; the capillary active system will lose its ability for moisture redistribution if there is not full contact between the materials in the system. Also, no organic material should exist at the cold surface of the insulation [20] and for systems with vapour barriers, proper installation and complete tightness is needed. Furthermore, these systems leave the wall extra sensitive to external moisture loads, as inward drying is limited.

There has been increasing focus on internal insulation in heritage buildings for the past few years; a limited number of studies with long-term in situ measurements are available. Orlik-Kożdoń et al. [11] found no critical moisture conditions in two cases of internal insulation of expanded polystyrene and lightweight aerated concrete on a solid brick wall. However, measurements were performed for only 6 months, and furthermore, there was an external curtain wall, protecting the construction from external moisture loads etc. Klõšeiko et al.[13][21] on the other hand, obtained high relative humidities in four cases of internal insulation on a brick wall during a 9 month study. The four materials tested in this case include; calcium silicate $50 \mathrm{~mm}$, aerated concrete (AAC) $60 \mathrm{~mm}$, polyurethane foam (PUR) with capillary active calcium silicate channels in a grid of 40X40mm (IQ-Therm) $50 \mathrm{~mm}$ and polyisocyanurate foam (PIR) $30 \mathrm{~mm}$. Calcium silicate proved the best performance in regard to moisture performance, however calcium silicate also has the highest thermal conductivity. Harrestrup et al. [22] monitored a case of internal insulation of 40mm aerowolle on a heritage brick building, and the effect of intentional thermal bridges above and below supportive wooden beams. They found that leaving a 200mm uninsulated gap above and below the beams yielded a lower risk of mould growth, however this was found to be very dependent on the orientation and the thickness of the existing wall. Toman et al. [8] ran a long-term study of 4 years, on a $19^{\text {th }}$ century building, with solid brick walls, external render and paint, insulated with a hydrophilic mineral wool insulation board, and no vapour barrier, however, a vapour retarder was placed on the interior surface of the existing wall. The study showed excellent hygrothermal conditions and no risk of interstitial condensation at any point in time during the 4 year period. In a recent study by Hamid et. al. [23], a similar study was performed with in situ measurements in solid masonry with internal insulation, and validated simulation models. The study emphasized the importance of the orientation due to the significant influence of wind driven rain, and solar driven vapour. Furthermore, the study emphasized the significant risk of mould growth at the wall-insulation interface, and the cold side of an integrated vapour barrier given the presence of biological material. 
This study aims to add to the knowledge of internal insulation systems by investigating the success or failure of two different insulation systems and thicknesses on four different case buildings with long-term monitoring in real climate conditions. Initially the measurements were initiated in order to gain empirical data for research of internal insulation of historical brick buildings with regard to moisture performance of the wall and beam ends. Based on the measured data, and hygrothermal simulations performed in Delphin 5.8 [24], it is sought to gain an understanding of how internal insulation can safely be applied.

\section{Method}

The presented study is built around long-term monitoring of hygrothermal performance of historic building façades retrofitted with internal insulation. Monitoring results are assessed with mathematical risk models and with 1D hygrothermal numerical simulations. In the case of Meinungsgade, the $1 \mathrm{D}$ simulation has also been verified by 2D simulations.

\subsection{Insulation systems}

Two different insulation systems with different insulation thicknesses are studied. In total, four cases are presented. Both insulation materials in this study are highly insulating rigid foams, however they are initially not vapour permeable or capillary active potentially trapping possible moisture accumulation. One of the systems included in this study, system 2, has been provided with channels of calcium silicate with the purpose of enabling capillary transport of possible condensate, as well as leaving the system vapour permeable. The complete insulation systems in this study are set up as fully adhered to the existing wall and the systems are described in Table 1; 
Table 1: Internal insulation systems used in the presented cases.

\begin{tabular}{|c|c|c|}
\hline & Insulation material & Complete system \\
\hline System 1 & $\begin{array}{l}\text { Phenolic foam boards } \\
\text { (Kingspan Kooltherm K17 insulated } \\
\text { plasterboard) } \\
\lambda=0.020 \mathrm{~W} / \mathrm{mK}\end{array}$ & 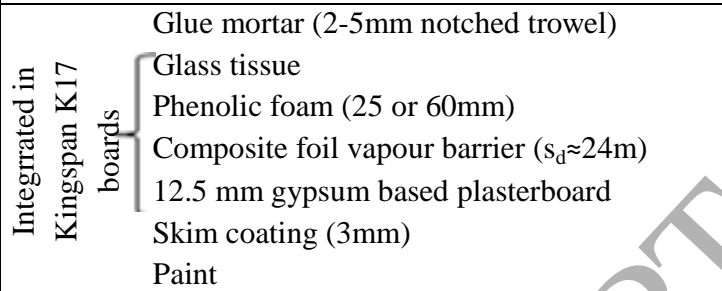 \\
\hline System 2 & $\begin{array}{l}\text { Polyurethane (PUR) foam with calcium } \\
\text { silicate channels in a grid of } 40 \mathrm{X} 40 \mathrm{~mm} \text { (IQ- } \\
\text { Therm) } \\
\lambda=0.037 \mathrm{~W} / \mathrm{mK}\end{array}$ & $\begin{array}{l}\text { IQ-Fix glue mortar }(2-5 \mathrm{~mm} \text { notched trowel) } \\
\text { IQ-Therm PUR foam ( } 30 \text { or } 80 \mathrm{~mm}) \\
\text { IQ-Top (porous light mortar) } \\
\text { IQ-Tex (glass tissue) } \\
\text { IQ-top (porous light mortar, } 10-15 \mathrm{~mm} \text { total) } \\
\text { IQ-Fill (fine putty) } \\
\text { Diffusion open paint (e.g. IQ-Paint) }\end{array}$ \\
\hline
\end{tabular}

The two systems have thermal conductivities of $0.02 \mathrm{~W} / \mathrm{mK}$ and $0.037 \mathrm{~W} / \mathrm{mK}$ for system 1 and system 2 respectively. In

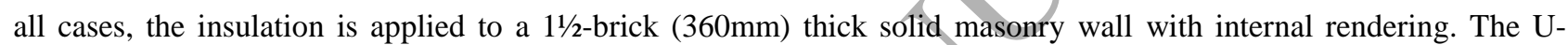
values are estimated based on an assumed identical brick type and the theoretical U-value reductions in each are displayed in Table 2 together with an overview of the presented cases. Each case is elaborated in sections 2.2.1-2.2.4.

Table 2: Overview of the four cases including the calculated U-values.

\begin{tabular}{|c|c|c|c|c|c|c|}
\hline Case & $\begin{array}{l}\text { Year of } \\
\text { construction }\end{array}$ & & Ext surface & $\begin{array}{l}\text { Insulation } \\
\text { system } \\
(\text { see Table 1)+ } \\
\text { thickness }\end{array}$ & $\begin{array}{l}\text { Theoretical } \\
\text { retrofitted U- } \\
\text { value } \\
{\left[\mathrm{W} / \mathrm{m}^{2} \mathrm{~K}\right]}\end{array}$ & $\begin{array}{l}\text { Theoretical } \\
\text { U-value } \\
\text { reduction } \\
{[\%]}\end{array}$ \\
\hline Ny Allegade & 1932 & $2^{\text {nd }}$, East + South & Blank & $2,80 \mathrm{~mm}$ & 0.35 & 75 \\
\hline Meinungsgade & 1877 & $5^{\text {th }}$, South + Southwest & Blank & $1,60 \mathrm{~mm}$ & 0.27 & 81 \\
\hline Kildevældsgade & 190 & $4^{\text {th }}$, North & $\begin{array}{r}\text { Render + } \\
\text { paint }\end{array}$ & $1,25 \mathrm{~mm}$ & 0.50 & 64 \\
\hline Th. Laubs Gade & 1899 & $4^{\text {th }}$, East & Blank & $2,30 \mathrm{~mm}$ & 0.65 & 53 \\
\hline
\end{tabular}

\subsection{In situ measurements and case buildings}

In all cases, temperature and relative humidity sensors of the type Rotronic HygroClip2 (accuracy $\pm 0.8 \%$ RH, $\pm 1 \mathrm{~K}$, up to $90 \% \mathrm{RH}$ ) have been installed at the interfaces between the original wall, and the insulation, as well as at the end of the beams. The case of Thomas Laubs Gade however, only has sensors at the wall-insulation interface. These are considered the areas of interest, as this is where potential risks concerning damaging moisture can arise. At the interfaces, there is an increased risk of interstitial condensation, which produces e.g. the risk of mould growth. The same goes for the beam ends with an increased risk of wood rot, as the drying potential and temperature are reduced when internal insulation is applied, and thus increasing the relative humidity. The sensors at the interfaces are placed in 
either existing joints, or purposely designed notches in the existing wall. Sensors behind beam ends are placed through holes drilled in the beam, and the holes then sealed with foam. Examples of sensor locations can be seen in Figure 1.
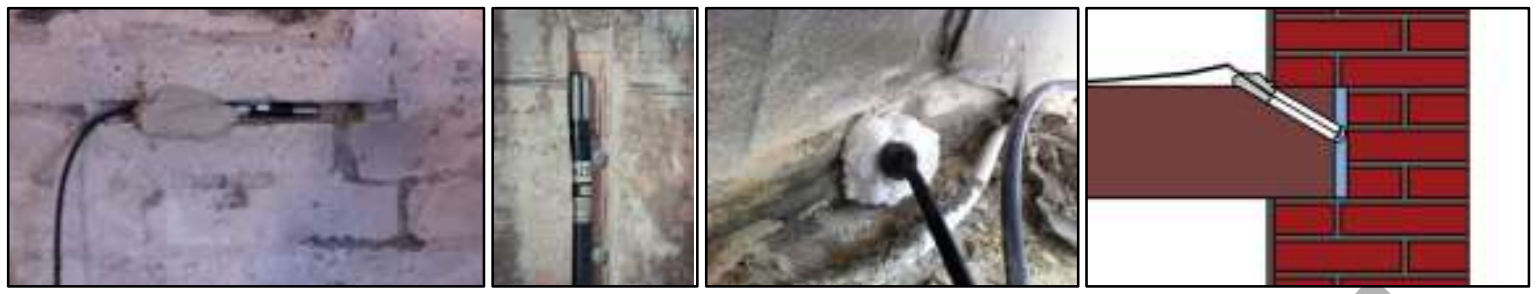

Figure 1: Sensor locations. From left to right; sensor in existing joint, purposely designed notch and in hole through beam end.

The sensors are set to log every 1 minute; and hourly averages have been generated and will be presented in the results section. The data was acquired by an online system provided by the company Electromec Engineering Service. The test buildings presented in this paper, are all multistory residential brick buildings from 1877-1932, built in a traditional Danish building style, with wooden beams and wooden lath to support intermediatefloors. The four cases are located in Denmark; three of them in Copenhagen, and one in Haderslev.

\subsubsection{Ny Allegade 10, Haderslev}

The case building in Haderslev is a 2 story building from 1932, with a bare brick surface, as seen in Figure 2. In the spring of 2015, 80mm of system 2 (30mm at spandrels) was installed on the west and south facades of both the $1^{\text {st }}$ and $2^{\text {nd }}$ floor. Figure 2 also displays the sensor locations on the floor plan, and construction plan. Sensor I1 represents interior conditions, sensors $\mathrm{W} 4, \mathrm{~W} 6$ and $\mathrm{W} 7$ represent conditions at the interface, and sensors B2, B3 and B5 represent conditions behind beam ends in the west orientated façade.

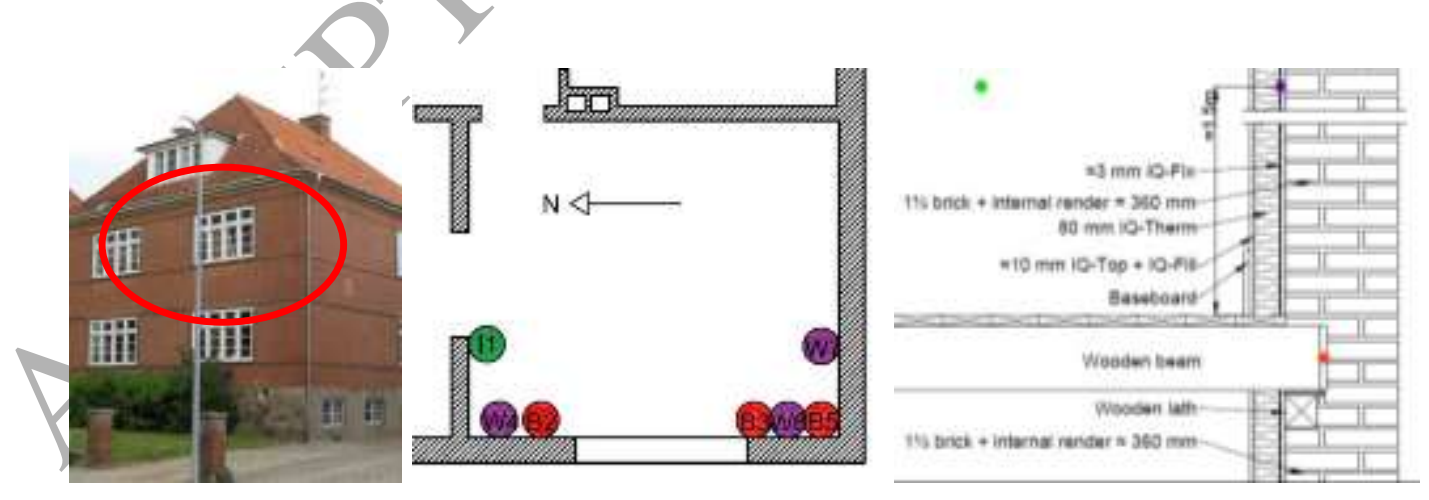

Figure 2: left to right; Ny Allegade facade with indication of insulated walls, sensor placement on floor plan, and construction with sensor placement. 


\subsubsection{Meinungsgade 1, Copenhagen}

This case building is from 1877, and the measurements are performed on the south and southwest walls on the $5^{\text {th }}$ floor. During the winter of 2015 the walls on the $4^{\text {th }}$ and $5^{\text {th }}$ floor, were insulated with $60 \mathrm{~mm}$ of system 1 (20mm for spandrels). Furthermore, a gap of $20 \mathrm{~cm}$ was left above the floor, for the creation of an intentional thermal bridge; the construction is seen in Figure 3. A floor plan with indications of sensor locations is also seen in Figure 3; sensor I1 represents interior conditions, sensors W2, W4 and W6 are placed at the interface; and sensors B3, B5 and B7 are behind the beam ends. Figure 3 also displays the façade, and as it can be seen, there is no visible surface treatment.
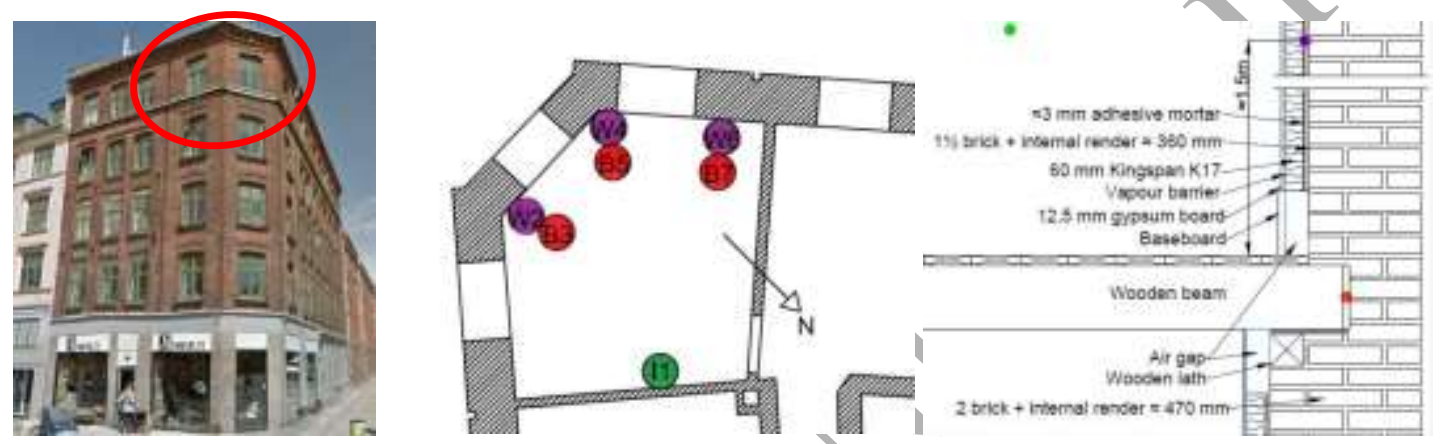

Figure 3: left to right; Meinungsgade facade with indication of insulated walls, sensor placement on floor plan, and construction with sensor placement.

\subsubsection{Kildevældsgade 69, Copenhagen}

The case on Kildevældsgade is a building from 1905, and has a rendered façade, as can be seen in Figure 4. 25mm of system 1 (20mm for spandrels) was installed in March 2015 on the northern façade of the $3^{\text {rd }}$ floor. As indicated in Figure 4, a $20 \mathrm{~cm}$ air gap above the beam was included for the intention of creating a thermal bridge, thus increasing the temperatures at the beam end. Figure 4 also displays a floor plan with an indication of sensor locations. Sensor I7 represents interior conditions, while sensors W2, W4 and W6 represent conditions at the wall-insulation interface, and sensors B1, B3 and B5 represent conditions behind the beam ends. Note that the floor beneath has not been insulated, and thus higher temperatures at the beam ends are expected compared to if both walls were insulated. 


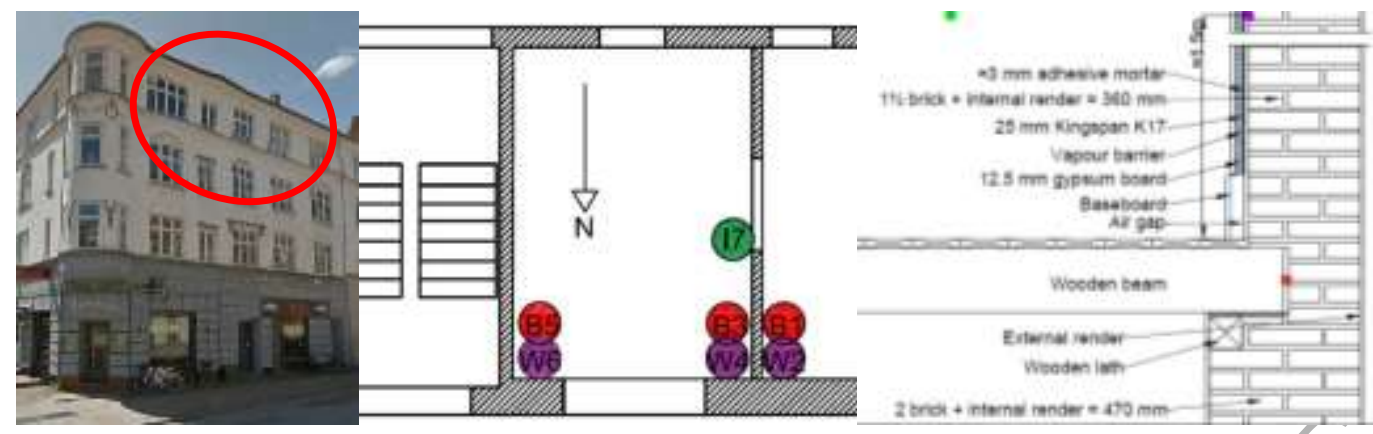

Figure 4: left to right; Kildevældsgade facade with indication of insulated walls, sensor placement on floor plan, and construction with sensor placement.

\subsubsection{Thomas Laubs Gade 5, Copenhagen}

The case on Thomas Laubs Gade is a building from 1899 with an exposed brick surface, as seen in Figure 5. The eastern façade on the $3^{\text {rd }}$ floor was in the fall of 2015 insulated with $30 \mathrm{~mm}$ system 2 except the spandrels which were insulated with $50 \mathrm{~mm}$ calcium silicate (SLP CS 50). Figure 5 also illustrates the floor plan with indication of sensor placements, and the construction. In this case there are no sensors in the beam ends. Sensor I4 presents the interior climate readings; sensor W3 is placed behind the calcium silicate in the spandrels, whereas sensor W1 is placed above sensor W2 at the interface between the insulation and the external wall. Unfortunately sensor W3 lost all contact during the summer of 2016. And all sensors lost connection for a period of about 3 months, March 2017 - June 2017.
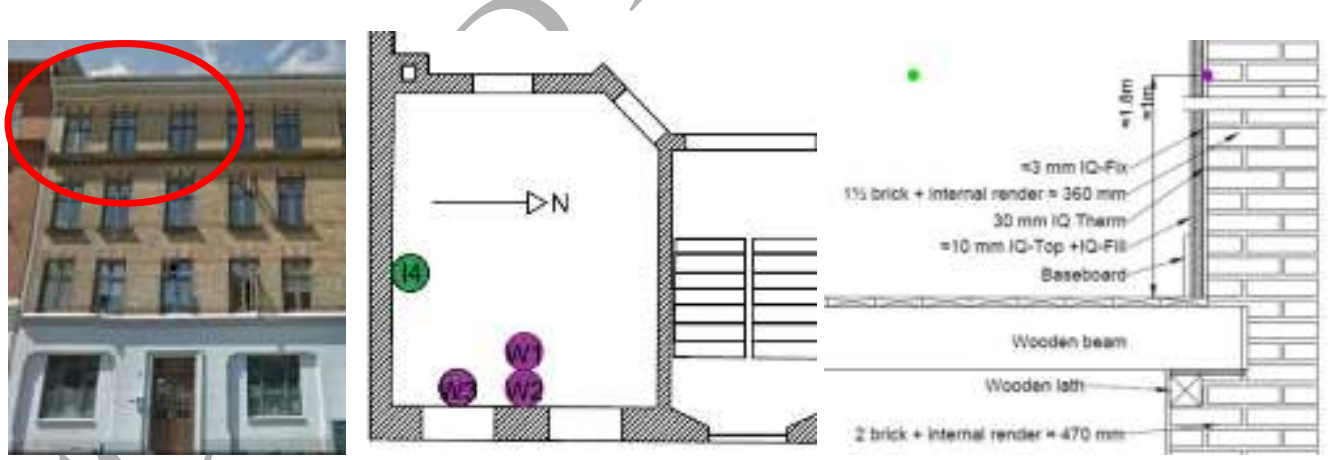

Figure 5: left to right; Thomas Laubs Gade facade with indication of insulated walls, sensor placement on floor plan, and

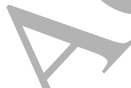
construction with sensor placement.

\subsection{Risk assessment model - mould index}

For assessment of risks associated with the altered hygrothermal conditions following installment of internal insulation, a risk assessment model for mould growth is introduced. The assessment is performed on measured data at the wallinsulation interface from the four case studies. . The risk assessment model provides a basis for comparison of the 
various hygrothermal conditions and associated risks. However, the risk assessment models - like the one used - should only be used relatively to give an indication for which solution gives a higher or lower potential for a risk.

In order to assess the mould risks in these cases, an improved mould model described in [25] and based on the original VTT mould growth model [26], was implemented. This model is one of the most acknowledged mould growth prediction models and takes benefit of the time dependence of the favorable mould growth conditions. A review of different mould models is found e.g. in [27], [28]. The original model was developed for prediction of mould growth on wooden surfaces, whereas the improved model takes sensitivity classes into consideration. The sensitivity classes are based on experimental results on various building materials [25]. The mould model can be implemented for the wallinsulation interfaces, however the mould growth intensity may be less, due to the limited air flow at the interface contra at the surface [29]. In the current study, the sensitivity class is set to medium resistant, corresponding to "cement or plastic based materials" and a relatively low decline $(0.25)$ during unfavorable growth conditions was implemented. Furthermore, the factors surface quality, SQ, and wood species, W, are included in the model and set to 0 for non-wood materials, and pine respectively. The mould index, M, quantifies the mould growth rate in a range from 0-6, elaborated in Table 3.

Table 3: Mould growth index classifications [25].

\begin{tabular}{|l|l|}
\hline $\begin{array}{l}\text { Mould } \\
\text { Index }(\mathbf{M})\end{array}$ & Description of growth rate \\
\hline 0 & No growth, spores not activated \\
\hline 1 & Small amounts of mould on surface (microscope), initial stages of local growth \\
\hline 2 & Several local mould growth colonies on surface (microscope) \\
\hline 3 & Visual findings of mould on surface, $<10 \%$ coverage, or, $<50 \%$ coverage of mould (microscope) \\
\hline 4 & Visual findings of mould on surface, 10-50\% coverage, or, $>50 \%$ coverage of mould (microscope) \\
\hline 5 & Plenty of growth on surface, $>50 \%$ coverage (visual) \\
\hline 6 & Very heavy and tight growth, coverage around $100 \%$ \\
\hline
\end{tabular}

The mould model is described in Equation 1, and the factors $\mathrm{k}_{1}$ and $\mathrm{k}_{2}$ represent intensity of growth and moderation of growth intensity in the late stage respectively. For determination of $\mathrm{k}_{1}$ and $\mathrm{k}_{2}$, time factors are used; $\mathrm{t}_{\mathrm{M}=1}$ represents the time needed for the growth to start (when $M$ reaches 1), and $t_{M=3}$ represents the time needed for the material to reach a mould index of 3 . Pine is the reference material, and why it is included in the calculations. $\mathrm{M}_{\max }$, the maximum mould index, depends on conditions and sensitivity class, in which the constants A, B and C are defined [25]. For the medium resistant sensitivity class, the parameters are given as: $\mathrm{A}=0, \mathrm{~B}=5$, and $\mathrm{C}=1.5$. $\mathrm{RH}_{\text {crit }}$ is the minimum limit to start the mould growth, dependent on the temperature [26] and the sensitivity class; 


$$
\begin{gathered}
\frac{d M}{d t}=\frac{1}{7 \cdot e^{-0.68 \ln (T)-13.9 \ln (R H)+0.14 W-0.33 S Q+66.02} \cdot k_{1} k_{2}} \\
k_{1}=\left\{\begin{array}{c}
\frac{t_{M=1, \text { pine }}}{t_{M=1}}, M<1 \\
2 \cdot \frac{t_{M=3, \text { pine }}-t_{M=1, \text { pine }}}{t_{M=3}-t_{M=1}}, M>1
\end{array}\right. \\
k_{2}=\max \left\{\begin{array}{c}
1-e^{2.3 \cdot\left(M-M_{\text {max }}\right)} \\
0
\end{array}\right. \\
M_{\text {max }}=A+B \cdot \frac{R H_{\text {crit }}-R H}{R H_{\text {crit }}-100}-C \cdot\left(\frac{R H_{\text {crit }}-R H}{R H_{\text {crit }}-100}\right)^{2}
\end{gathered}
$$

\subsection{Hygrothermal simulation}

1D simulations of the hygrothermal conditions in the wall-insulation interface of each of the four cases were carried out in Delphin 5 in order to study the long term performance of the specific cases as well as other variations of the studied systems. The models were first validated relative to measured data, yielding the possibility of forecasting the hygrothermal behavior of the cases in a longer perspective. The models for validation were built up as the constructions shown in Figure 2-Figure 5. For simplification, the preliminary simulations for initial validation of the 1-dimensional models were performed on both brick and lime mortar constructions, and the mortar wall yielded better results in regard to validation, as well as closer to results gained from a $2 \mathrm{D}$-simulation. Therefore the following simulations are performed on walls consisting of lime mortar. In addition, local weather data from Copenhagen and Haderslev from March 2015-March 2017, as well as measured indoor conditions, were used for the validations. Indoor boundary conditions were set to constant conditions of $22^{\circ} \mathrm{C}$ and $55 \% \mathrm{RH}$ for the future predictions. Material data for all materials was imported from the Delphin material library, with the exception of phenolic foam, which is based on extruded polystyrene board from the Delphin material database, altered in accordance to generic material parameters for phenolic foam and product specific information given by the manufacturer [30]. Material parameters are presented in Table 4. Thus the validation was achieved by constructing the 1D model with the correct layer thicknesses and assumptions in regards to the existing materials, and the climate files being similar to the local climate. Furthermore, assumptions on various exchange coefficients, including the rain exposure coefficients and absorption coefficient of the surface in regards to short wave radiation. As $1 \mathrm{D}$ simulations are performed, it should be noted that insulation system 2 is assumed homogenized despite the calcium silicate channels, however the material has been defined in the material database as one material. Hence the result may deviate from reality on this basis. In the cases of insulation system 1, two versions of each case have been simulated, as explained in section 3.3. 
Table 4: Material parameters for hygrothermal simulations in Delphin 5.

\begin{tabular}{|c|c|c|c|c|c|}
\hline & $\begin{array}{l}\text { Dry density } \\
\rho[\mathrm{kg} / \mathrm{m} 3]\end{array}$ & $\begin{array}{l}\text { Thermal } \\
\text { conductivity } \\
\lambda[\mathrm{W} / \mathrm{mK}]\end{array}$ & $\begin{array}{l}\text { Water uptake } \\
\text { coefficient } \\
\text { Aw }\left[\mathrm{kg} / \mathrm{m}^{2} \mathrm{~s}^{1 / 2}\right]\end{array}$ & $\begin{array}{l}\text { Water vapour diffusion } \\
\text { resistance factor } \\
\mu[-]\end{array}$ & $\begin{array}{l}\mathrm{S}_{\mathrm{d}} \text {-value } \\
{[\mathrm{m}]}\end{array}$ \\
\hline External render & 1570 & 0.7 & 0.18 & 11 & \\
\hline Existing wall & 1800 & 0.82 & 0.13 & 12 & \\
\hline $\begin{array}{l}\text { Adhesive/glue mortar } \\
\text { - system } 1\end{array}$ & 830 & 0.16 & 0.0031 & 13 & \\
\hline $\begin{array}{l}\text { Adhesive/ glue } \\
\text { mortar - system } 2\end{array}$ & 1313 & 0.50 & 0.0051 & 19 & \\
\hline $\begin{array}{l}\text { Insulation material - } \\
\text { system } 1\end{array}$ & 35 & 0.020 & $8 \cdot 10^{-6}$ & $\begin{array}{l}33 \\
1\end{array}$ & \\
\hline $\begin{array}{l}\text { Insulation material - } \\
\text { system } 2\end{array}$ & 49 & 0.037 & 0.013 & & \\
\hline Vapour barrier & & & & & $\begin{array}{l}\mathrm{S}_{\mathrm{d} \text {,dif. open }}: 0.5 \\
\mathrm{~S}_{\mathrm{d} \text {,dif. tight }}: 100\end{array}$ \\
\hline Top layer - system 1 & 850 & 0.2 & 0.28 & 10 & \\
\hline Top layer - system 2 & 1269 & 0.48 & 0.22 & 14 & \\
\hline
\end{tabular}

After model validation, 10 year simulations were performed based on 10 years of forecasted weather data for 20202050 in Øster-Ulslev in Denmark, from the EU project Climate for Culture [31]. Finally, variations of each case were simulated in order to study the effect of insulation thickness (based on product specific thicknesses), material and rendered façade surface. The variations are described in Table 5 below;

Table 5: Simulation variations of each case.

\begin{tabular}{|l|l|l|l|l|}
\hline & Kildevældsgade & Meinungsgade & Ny Allegade & Thomas Laubs Gade \\
\hline Original & Paint + render & No render & No render & No render \\
& $25 \mathrm{~mm}$ system 1 & $60 \mathrm{~mm}$ system 1 & $80 \mathrm{~mm}$ system 2 & $30 \mathrm{~mm}$ system 2 \\
\hline Variation 1 & Paint + render & No render & No render & No render \\
Thickness & $60 \mathrm{~mm}$ system 1 & 30mm system 1 & $30 \mathrm{~mm}$ system 2 & $80 \mathrm{~mm}$ system 2 \\
\hline Variation 2 & No render & Paint + render & Paint + render & Paint +render \\
Render & $25 \mathrm{~mm}$ system 1 & $60 \mathrm{~mm}$ system 1 & $80 \mathrm{~mm}$ system 2 & $30 \mathrm{~mm}$ system 2 \\
\hline Variation 3 & Paint + render & No render & No render & No render \\
Insulation & $30 \mathrm{~mm}$ system 2 & $60 \mathrm{~mm}$ system 2 & $80 \mathrm{~mm}$ system 1 & $30 \mathrm{~mm}$ system 1 \\
system & & & & \\
\hline
\end{tabular}

\section{Results and discussion}

\subsection{In situ measurements}

Measurements for each case are presented as hourly averages generated from minutely data. A relative humidity of $85 \%$ is considered the minimum relative humidity for initiation of mould growth during long term exposure for very 
medium resistant materials, e.g. concrete and glass wool [25], why this is considered the threshold value in the following paragraphs.

\subsubsection{Ny Allegade, Haderslev, 80mm system 2}

Hourly averages of measurements performed are presented in Error! Reference source not found.. The relative humidities at both wall interfaces and cavities behind the beam ends are above $95 \%$ during the measurement period, with the exception of sensor B2. During the $2 \frac{1}{2}$ year measurement period, there is no indication of significantly reduced relative humidity in either the wall interfaces or behind the beam ends. It is a known fact that built-in moisture, due to the installation of internal insulation takes time to dry out, but after the first year the installation moisture from the glue mortar can be considered of no influence [29]. There is no observable difference in wall measurements on the west and south façades. The outlier, sensor B2 however, exhibits acceptable conditions below $80 \%$ relative humidity for the entire period. Sensor B2 is placed towards the middle of the wall, as opposed to B3 and B5, which may reduce the impact of driving rain in this position [32]. The temperature measurements however, also reveal higher temperatures at B2 during winter, thus increasing the drying potential. The higher temperature may indicate the placement of a hot water pipe or the like, or that the sensor is not placed at the end of the beam, but rather within the beam, and thus closer to the warmer interior conditions. Also, the beam end might be dryer than the cavity behind the beam, as the wood fibers of the beam end transport the moisture inwards. In these cases, the measurements in B2 are not representative and should be discarded. The measured interior conditions seem stable at $20^{\circ} \mathrm{C}$ and seasonal variation of $30-70 \% \mathrm{RH}$. The interior conditions do not seem to effect the hygrothermal conditions in sensor locations, although temperature measurements in sensors resemble the interior temperature during summer seasons.

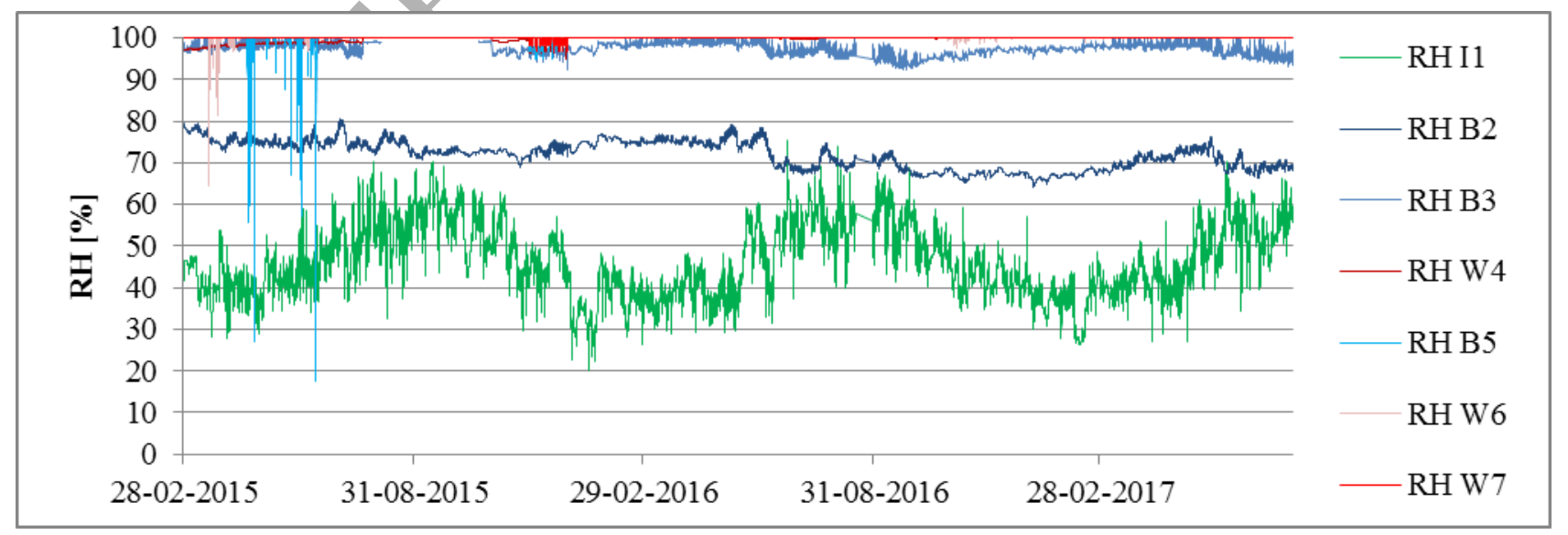




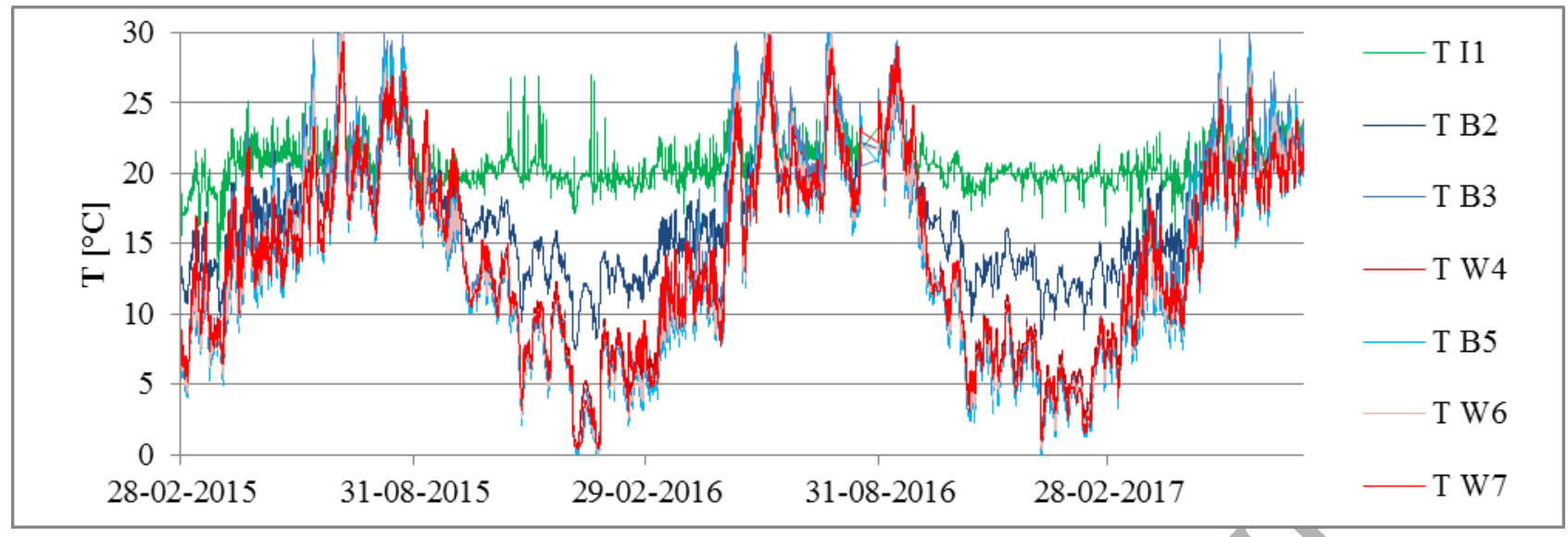

Figure 6: Measured hygrothermal conditions measured in Ny Allegade (80mm, system 2, western (W4, W6, B2, B3, B5) and southern (W7) façade). The blue nuances represent sensors behind the beam ends, whereas the red colors represent sensors at the wall-insulation interface.

\subsubsection{Meinungsgade, Copenhagen, 60mm system 1}

Generated hourly averages from measurements performed in Meinungsgade are represented in Error! Reference source not found.. For wall interfaces, sensors W2 and W4, it is seen that the relative humidity rarely exceeds $80 \%$. It is seen that for warmer periods, the relative humidity resembles interior conditions, whereas the external moisture influences during winter are apparent, as the relative humidity increases. The integrated vapour barrier inhibits drying inwardly in the colder periods when the masonry becomes moist. The relative humidity at the wall interfaces fluctuates between $40-80 \%$ which is considered acceptable. In the first 2 years, sensor W6 generally exhibits higher relative humidity. This sensor is located by an indentation in the wall for the previous installation of a downspout. This indentation makes the wall thinner, thus the penetration of wind driven rain may reach closer to the sensor. The indentation furthermore limits the drying potential in form of both radiation and wind. Additionally, sensor W6 is placed in southwest orientation as opposed to south, as W2 and W4. This again contributes to more wind-driven rain and less sun at W6 compared to W2 and W4. The conditions behind the beam ends are rather high, 70-90\%, during the first 2 years of measurements. For the last months of measurements, the relative humidity barely exceeds $80 \%$. Neither weather data from Copenhagen or interior conditions indicate any obvious explanations for the 2-year drying period. The beam ends are embedded in the wall, so the external wall is thinner at the location behind the beam ends, thus leaving this area more exposed to external conditions, such as penetrating wind-driven rain. The intentional thermal bridges do not seem to have the desired effect; the temperature behind the beam ends is the same, or less than, the temperature at the wall interfaces. The temperature conditions show very similar results for all sensors. During summer, the temperatures resemble the interior conditions. This tendency also applies to the relative humidity measurements after the initial drying period. 


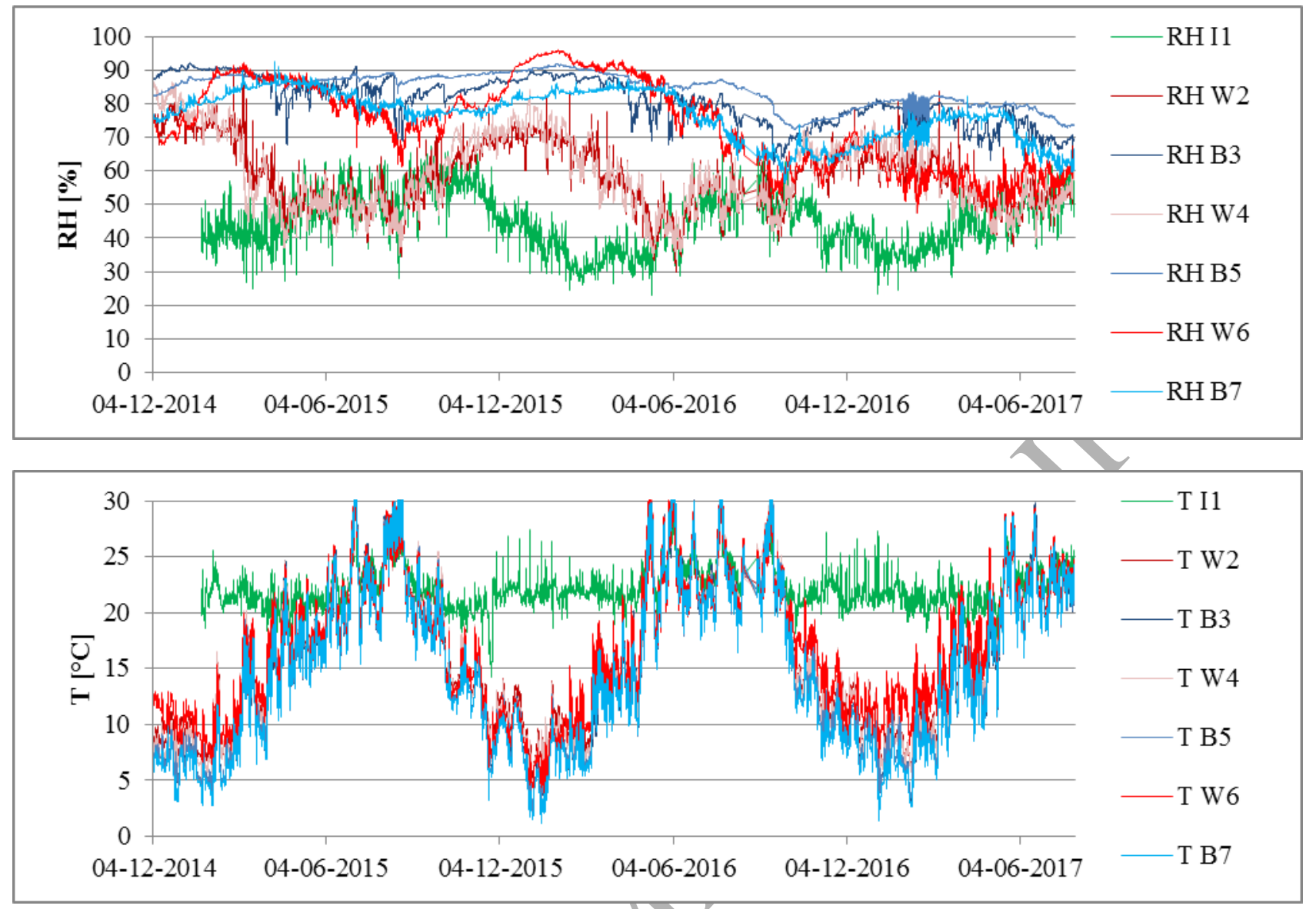

Figure 7: Measured hygrothermal conditions in Meinungsgade $(60 \mathrm{~mm}$, system 1, southern (B3, W2) and southwestern (B5, B7, W4, W6) façade). The blue nuances represent sensors behind the beam ends, whereas the red colors represent sensors at the wall-insulation interface.

\subsubsection{Kildevældsgade, Copenhagen, $25 \mathrm{~mm}$ system 1}

In the case of internal insulation installed in Kildevældsgade, the initial building moisture and successive drying out period is very apparent; see Error! Reference source not found.. In the first 6 months, the relative humidity is very high in the wall interface, sensors W2, W4, W6, and hereafter a seasonal dependency is apparent, but the relative humidity does not exceed $80 \%$. During the course of measurements, sensor W6 exhibits a significantly faster decline and generally lower relative humidity compared to the other wall sensors. There is a slightly higher temperature measured by W6, and by studying pictures from the installment of insulation, it is seen that hot water pipes are installed in the vicinity of sensor W6, increasing the drying potential in this area. The beam end sensors also do not exceed $80 \%$ relative humidity, with the exception of sensor B1 that exceeds $80 \%$ for shorter periods during the first winter. It is seen that sensor B5 has the lowest relative humidity, and again this can be explained by a slightly higher temperature, or possibly the location of the sensor not drilled all the way into the cavity behind the beam end. The temperature and 
relative humidity both behind the beam ends and at the wall-insulation interfaces resemble the interior conditions measured.
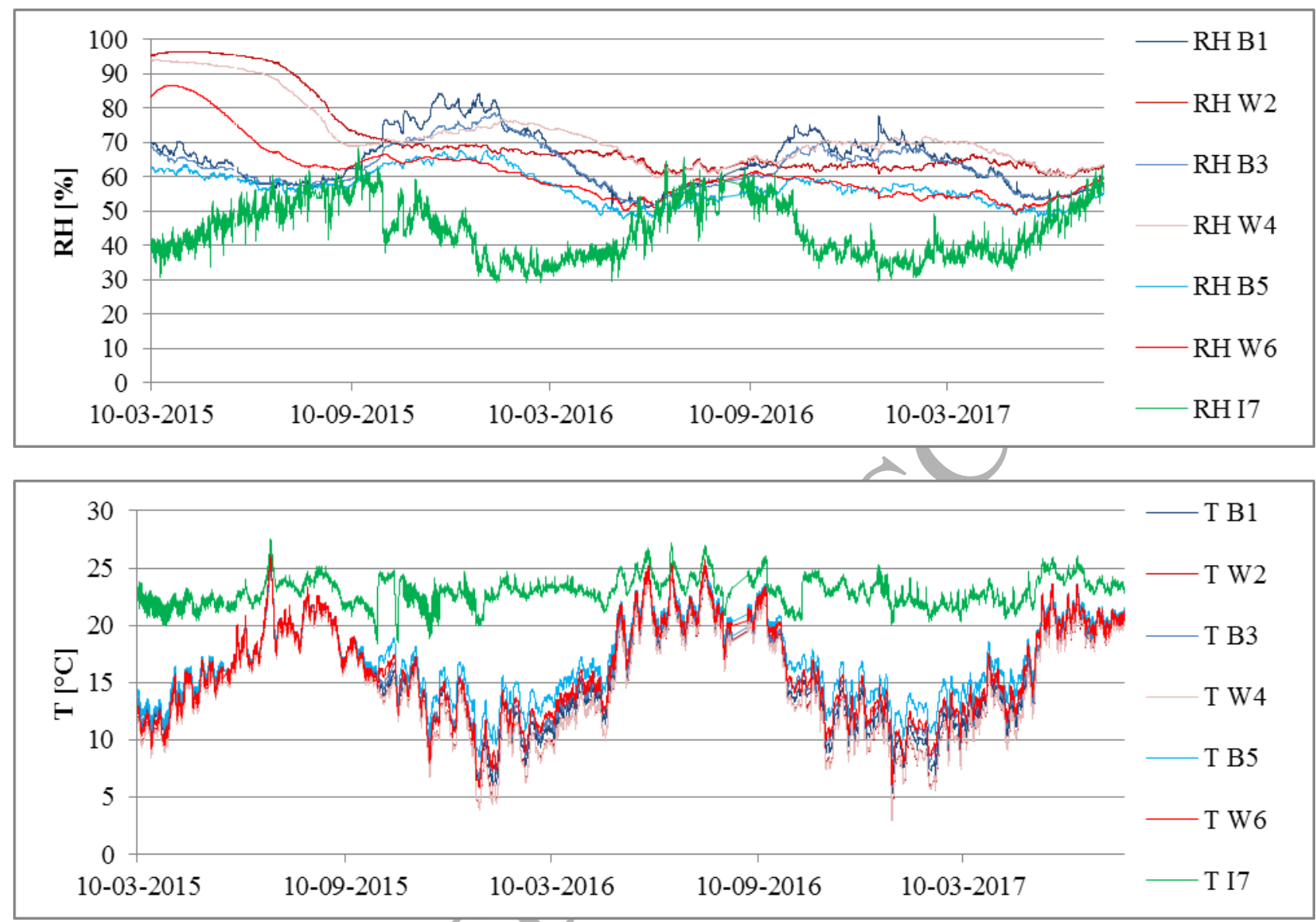

Figure 8: Measured hygrothermal conditions in Kildevældsgade (25mm, system 1, southern (B3, W2) and southwestern (B5, B7, W4, W6) façade). The blue nuances represent sensors behind the beam ends, whereas the red colors represent sensors at the wall-insulation interface.

\subsubsection{Thomas Laubs Gade, Copenhagen, 30mm system 2}

At Thomas Laubs Gade, the relative humidity is initially very high, due to installing the insulation with a wet glue mortar. Despite unreliable sensors and missing data, a decline of the relative humidity is seen, Error! Reference source not found.. During the 20 months of measuring however, the relative humidity still exceeds $80 \%$ in sensor W2, whereas sensor W1 seems to decrease to acceptable conditions. For the initial period, sensor W1 exhibits the highest relative humidity, but also the lowest temperature. This is the sensor placed below the window. The spandrels are thinner (one brick thick with render $=240 \mathrm{~mm}$ ) and thus this measuring point is more exposed to exterior conditions. It 
is seen that the temperatures measured at the wall-insulation interfaces resemble the interior conditions during summer seasons.
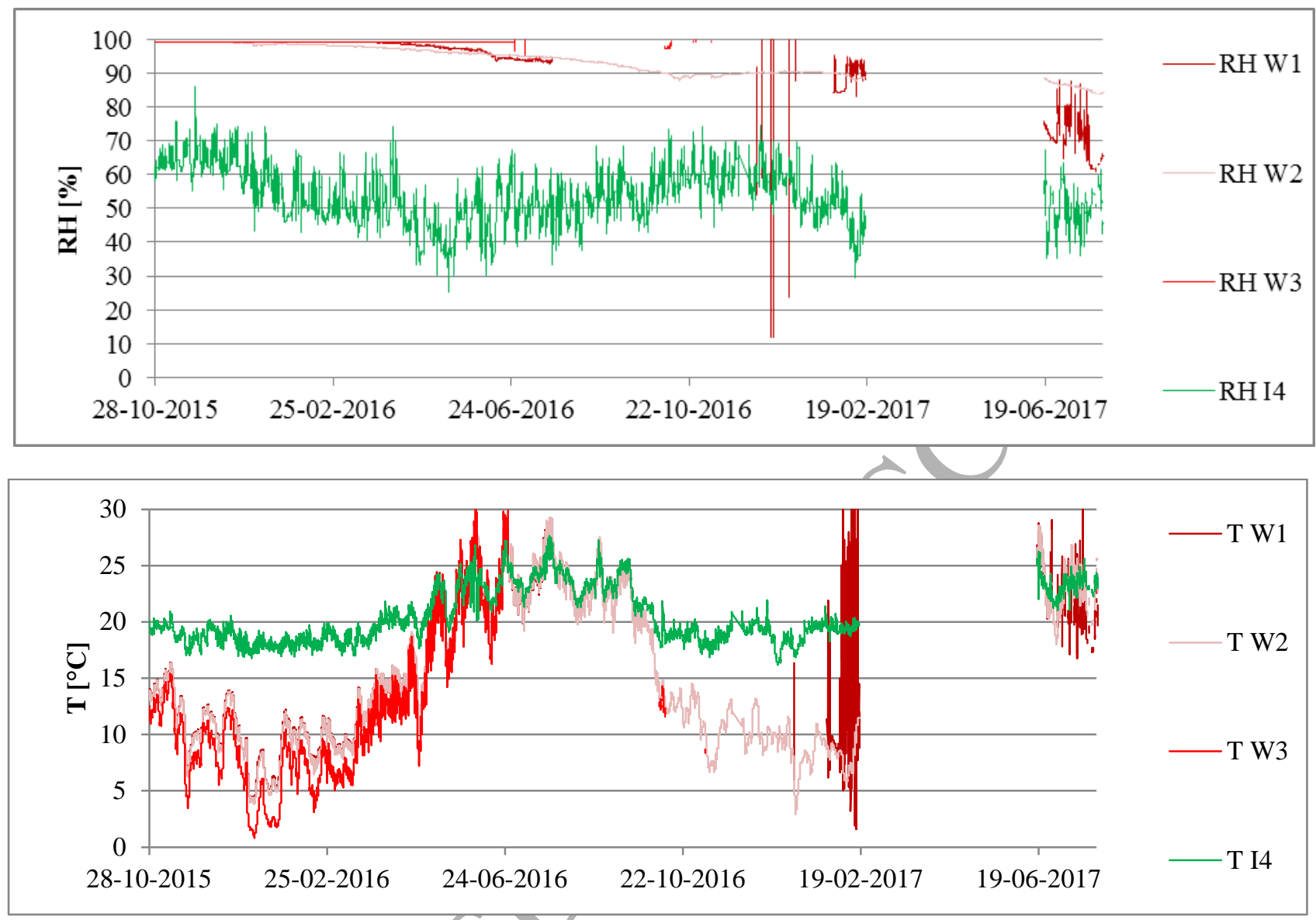

Figure 9: Measured hygrothermal conditions in Thomas Laubs Gade (30mm, system 2, eastern façade). The blue nuances represent sensors behind the beam ends, whereas the red colors represent sensors at the wall-insulation interface.

\subsection{Hygrothermal assessment of the measurements - mould index}

The assessment of the hygrothermal performance of the post insulated façades with damage model (Mould Index) is presented graphically in this section Furthermore, due to the expected increasing uncertainty of the measured relative humidity, the assessment has been performed as well on measured data as $+5 \% \mathrm{RH}$ for relative humidity above $90 \%$ $\mathrm{RH}$ in each case. The results for $+5 \%$ relative humidity are presented with dashed lines. The results for the damage models are presented in Figure 10. The data from Thomas Laubs Gade is unfortunately insufficient for generation of mould model, due of the large data gaps, as seen in Error! Reference source not found.. 


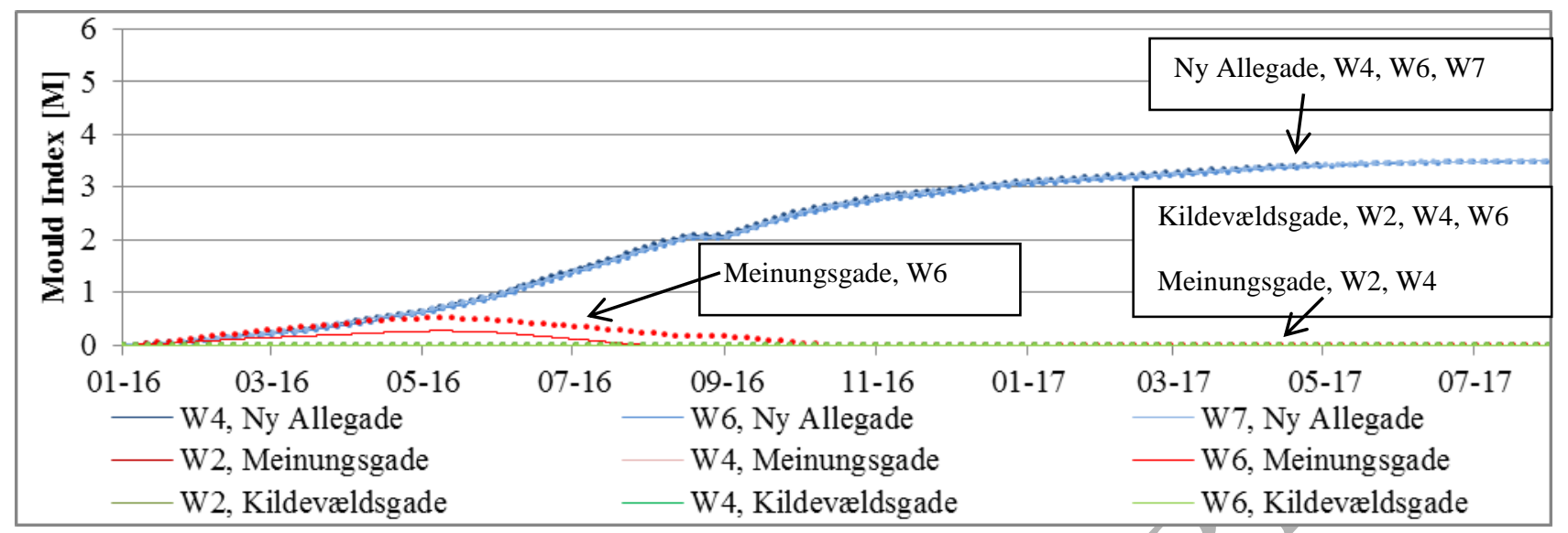

Figure 10: Mould index for wall-insulation interfaces as a function of time. W: interface. Dashed lines represent cases where $5 \%$ uncertainty was added to measurements above $90 \%$ RH.

The basic alkaline conditions in the cementitious glue mortar, prevent mould growth for the first year of measurements, why these data have been excluded in the model calculations [29]. The calculated mould indexes are presented in Figure 10. It is seen that at Ny Allegade the measurements from all sensors yield mould indexes above 1, thus the theoretical risk of mould growth exists, and the conditions can be considered unacceptable. There is no sign of decline, as the measured RH is so high. In these cases, the mould index peaks at 3.5 and stays there. At Meinungsgade it is seen that for the measured values, the mould growth is only initiated for measurements of sensor W6, however it never exceeds Mould Index 1, not even with the uncertainty factor included. Furthermore, the mould index in this sensor declines to 0 after a short period. At Kildevældsgade there is no indication of risk of mould growth from any of the measured data.

\subsection{Hygrothermal simulations}

The quality of simulation results depends highly on the input variables, and there are numerous unknown parameters estimated in the performed simulations, they include material parameters of the existing walls as well as climate data being from nearby weather stations, and not necessarily representing e.g. wind patterns at the exact locations. However validated models were made based on measured data, and the following projections were based on the validated models. In general, as also seen in Figure 11, for the two cases of insulation with system 1 (phenolic foam), Kildevældsgade and Meinungsgade, good validation results could not be achieved. Initially insulation system 1 was simulated as diffusion tight, as phenolic foam is diffusion tight, and furthermore the system includes a vapour barrier. These simulations generated very different moisture levels than the measured data in the interface between insulation and the existing wall. By implementation of a model without a vapour barrier and reduced water vapour diffusion resistance factor of the insulation to $\mu=1.0$ better agreements were achieved, as seen in Figure 11. The discrepancies in simulation results are 
assumed to be caused by the installation method. In both cases, the insulation systems were installed with a $20 \mathrm{~cm}$ gap left at the bottom of the wall, for an intentional thermal bridge in order to achieve higher temperatures at the beam ends. The vapour barrier, incorporated in the insulation boards, was discontinued at the bottom gap as well as joints. In addition, a notched trowel was used for the glue mortar, and likely not smoothed out. Thus the plates were not fully bonded and yielded the possibility of convection or vapour diffusion in air pockets at the interface. For the 1D hygrothermal simulations, this air movement was attempted to be incorporated in the models, by alterations of the vapour diffusion resistance of the phenolic foam and removal of the vapour barrier, as stated above. Thus the further simulations include both the diffusion tight (fully bonded plates) and the diffusion open (validated model) version of insulation system 1. Simulations indicate, that despite the vapour barrier, and diffusion tight phenolic foam, the system performs diffusion open in the measured cases presented. In regards to $1 \mathrm{D}$ simulation, the application method is critical to avoid air channels behind the plates and hence allowing convection and vapour diffusion. This was taken into account by alteration of material parameters, and the achieved validations are illustrated in Figure 11. As it can also be seen in Figure 11, the simulation results resemble measured data mostly for summer and fall periods, whereas the relative humidity seems to lie a bit higher in the simulations for the winter periods. This means, that at least the models present results that are on the safe side according to moisture risks. The same tendency was found by Hamid et. al. [23].

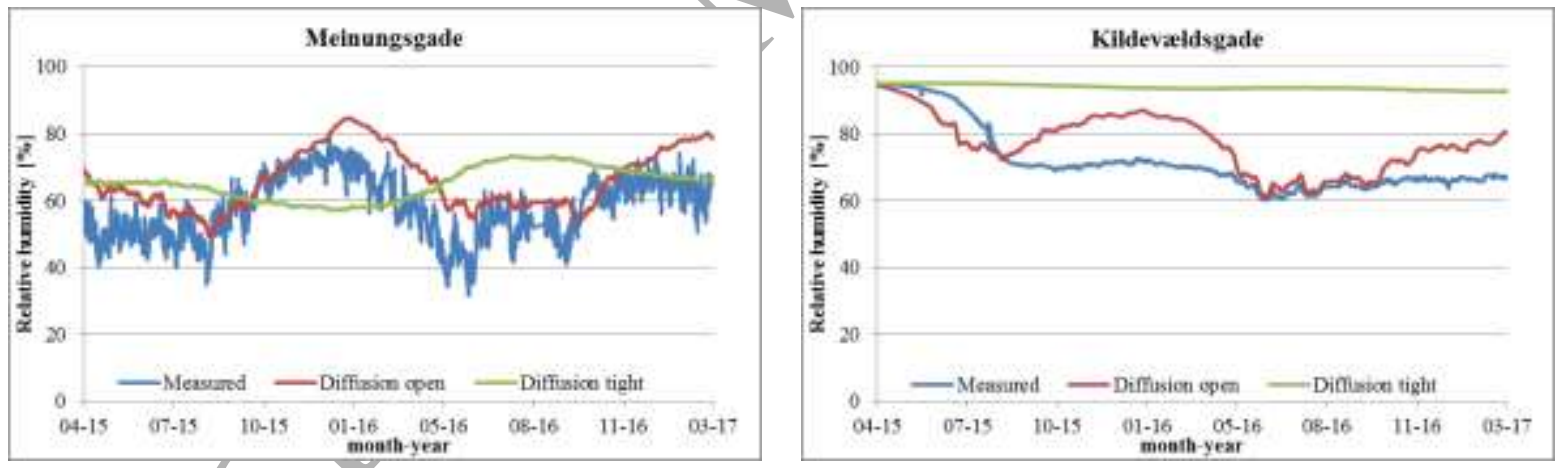

Figure 11: Validation of cases with insulation system 1 were achievable when making the phenolic foam diffusion open and omitting the vapour barrier.

10 year predictions for each case are represented in Figure 12. All cases show unacceptable hygrothermal conditions $(\mathrm{RH}>80 \%)$ during the 10 years of simulations - with the exception of the diffusion open version of insulation system 1. The worst moisture conditions appear to be in winter periods for the cases of insulation system 2 and diffusion open system 1. The case with $80 \mathrm{~mm}$ of insulation system 2 (Ny Allegade) appears to show the worst performance, whereas the case with only 30mm of system 2 insulation (Thomas Laubs Gade) appears to perform better during the 10 year 
period. Unacceptable conditions still apply however. The diffusion tight versions of Meinungsgade and Kildevældsgade, both insulated with system 1, show significantly less seasonal variation. The diffusion open version of system 1 exhibits significantly more seasonal variations and only unacceptable conditions during winter periods.

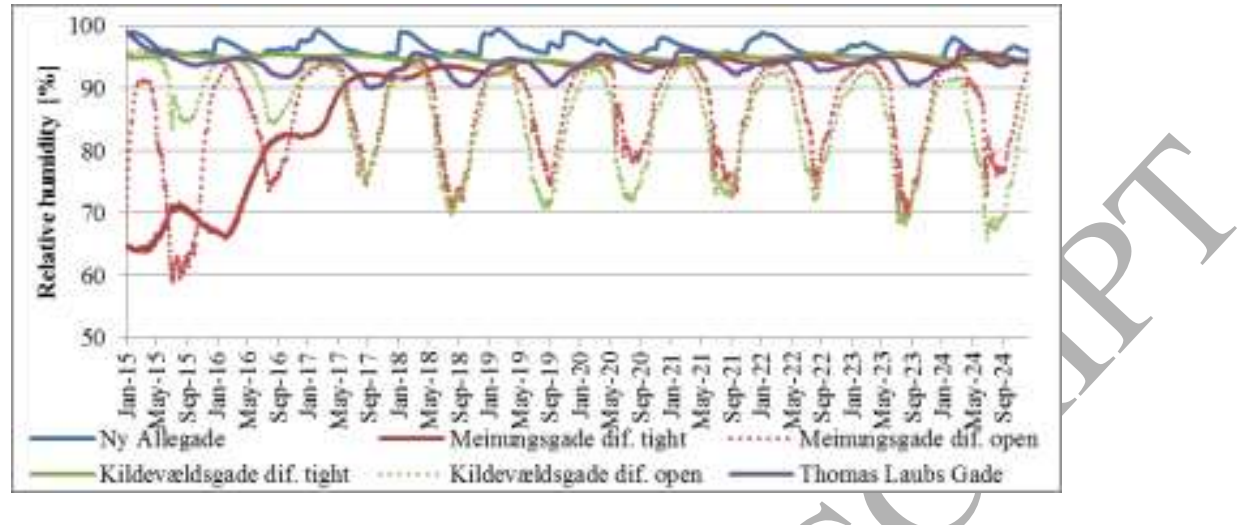

Figure 12: 1-dimensional simulations for 10 years of each presented case at the wall-insulation interfaces. The dotted lines represent the diffusion open version of insulation system 1.

In Figure 13 the results from the parameter variations are presented for each case. In each case, the original model is presented in blue, the thickness variation in red, the external surface with/without render in green, and finally the variation between the insulation systems is depicted in purple Kildevældsgade with system 2 insulation rather than system 1 , is the only case that exhibits a tendency of reduced relative humidity during the 10 year period. For the cases of insulation system 1 (Meinungsgade and Kildevældsgade), it is apparent, that the diffusion open version yields better hygrothermal conditions at the interface.
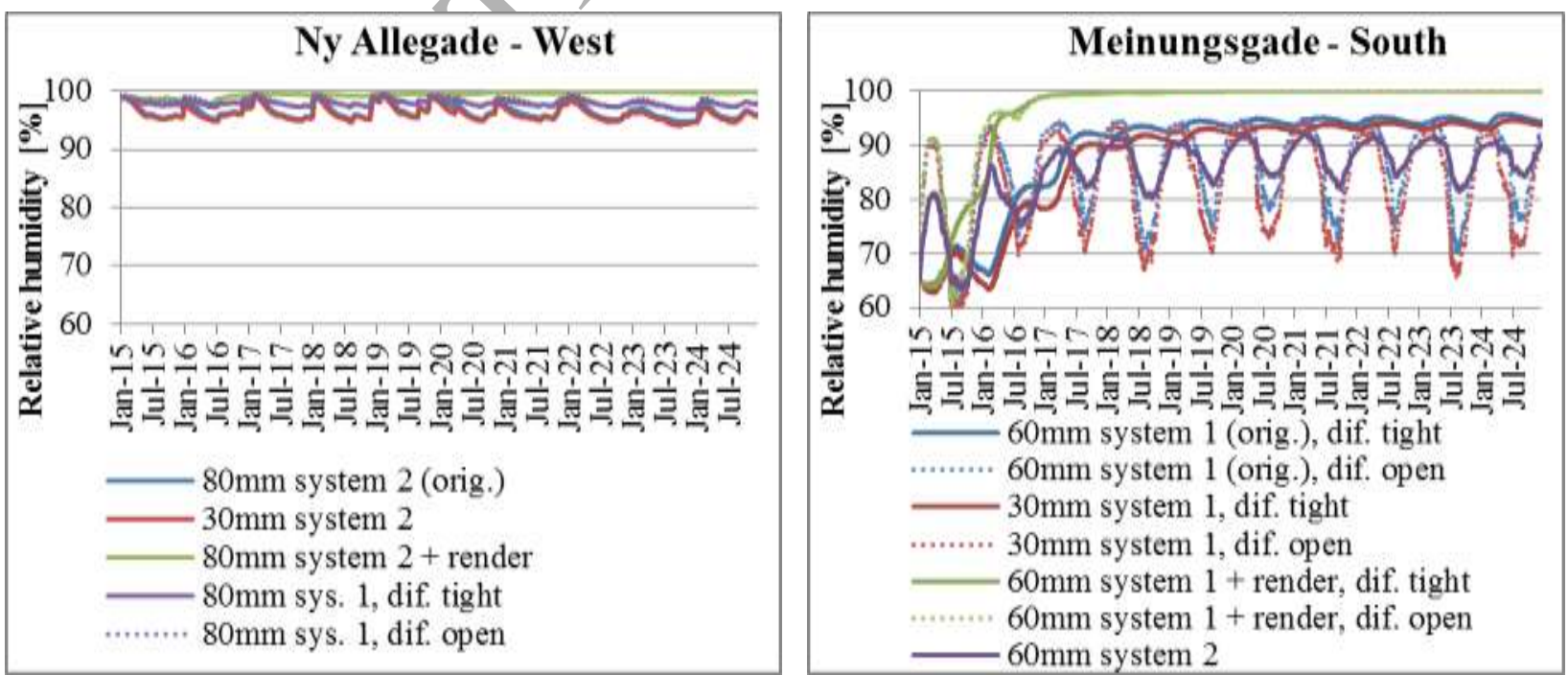

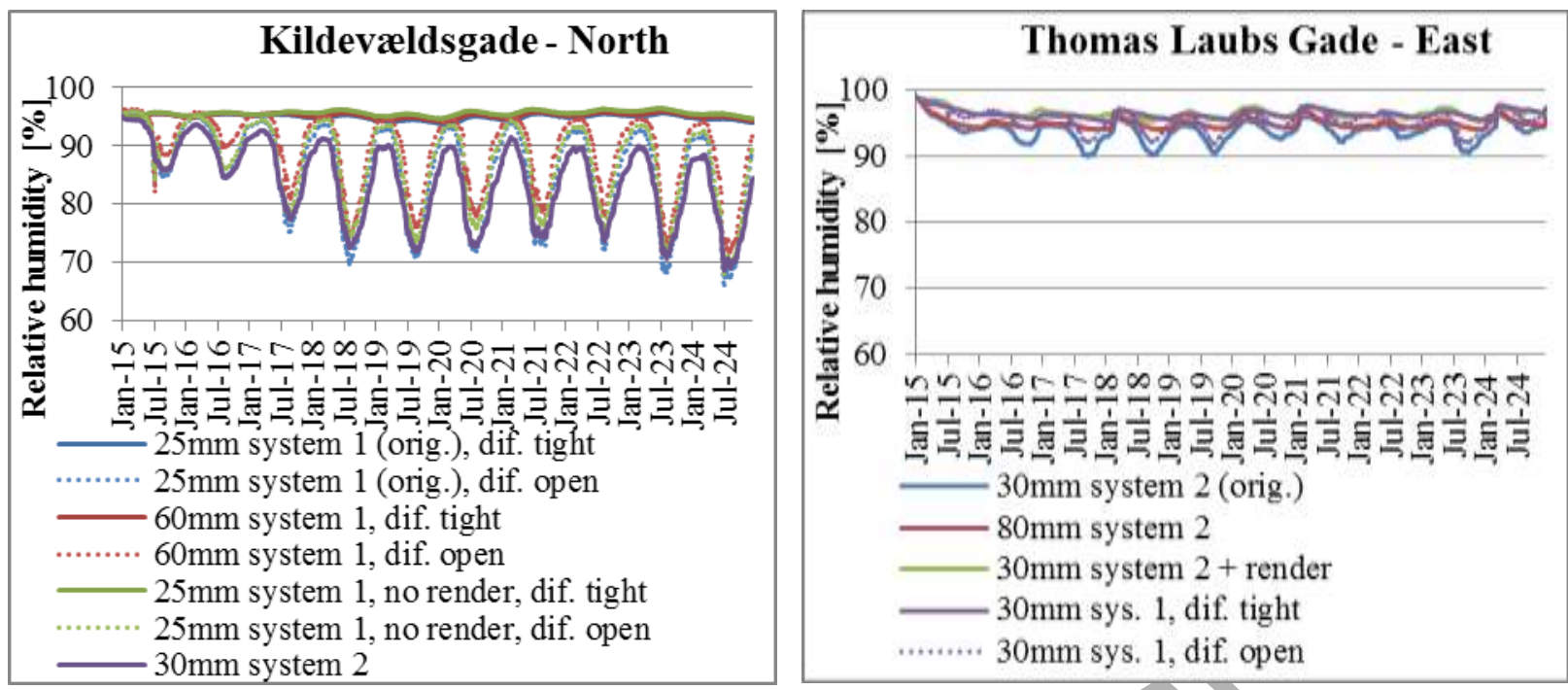

Figure 13: 10 year simulation variations of insulation thickness, external surface (with/without render) and insulation system.

The mould indexes for the four 10-year simulations are illustrated in Figure 14. For both cases with insulation system 2 (Ny Allegade and Thomas Laubs Gade), the mould index quickly (reaches a steady maximum value of 3.3 and 3 respectively, for all the variations implemented, and thereby presenting a high risk of visual findings of mould growth. As seen in the relative humidities displayed in Figure 13, these two cases have continuously high relative humidities and minimal the seasonal variation thus leading to optimal mould growth criteria. The risk of mould growth is also apparent in both cases of insulation system 1. The risk of mould growth is significantly less, when insulation system 2 is applied to these cases. In the case of Meinungsgade, the largest display of the effects of the variations is seen. The addition of external render to the surface yields a higher mould index. This could be attributed to the reduction in drying potential from the sun and increased diffusion resistance on the southern façade, which is the most exposed to wind driven rain. The reduction of insulation thickness yields a slightly reduced mould index, which can be expected. It is also seen that the diffusion open version of system 1 yields more seasonal variation, and in general a lower risk of mould growth in the long run. 

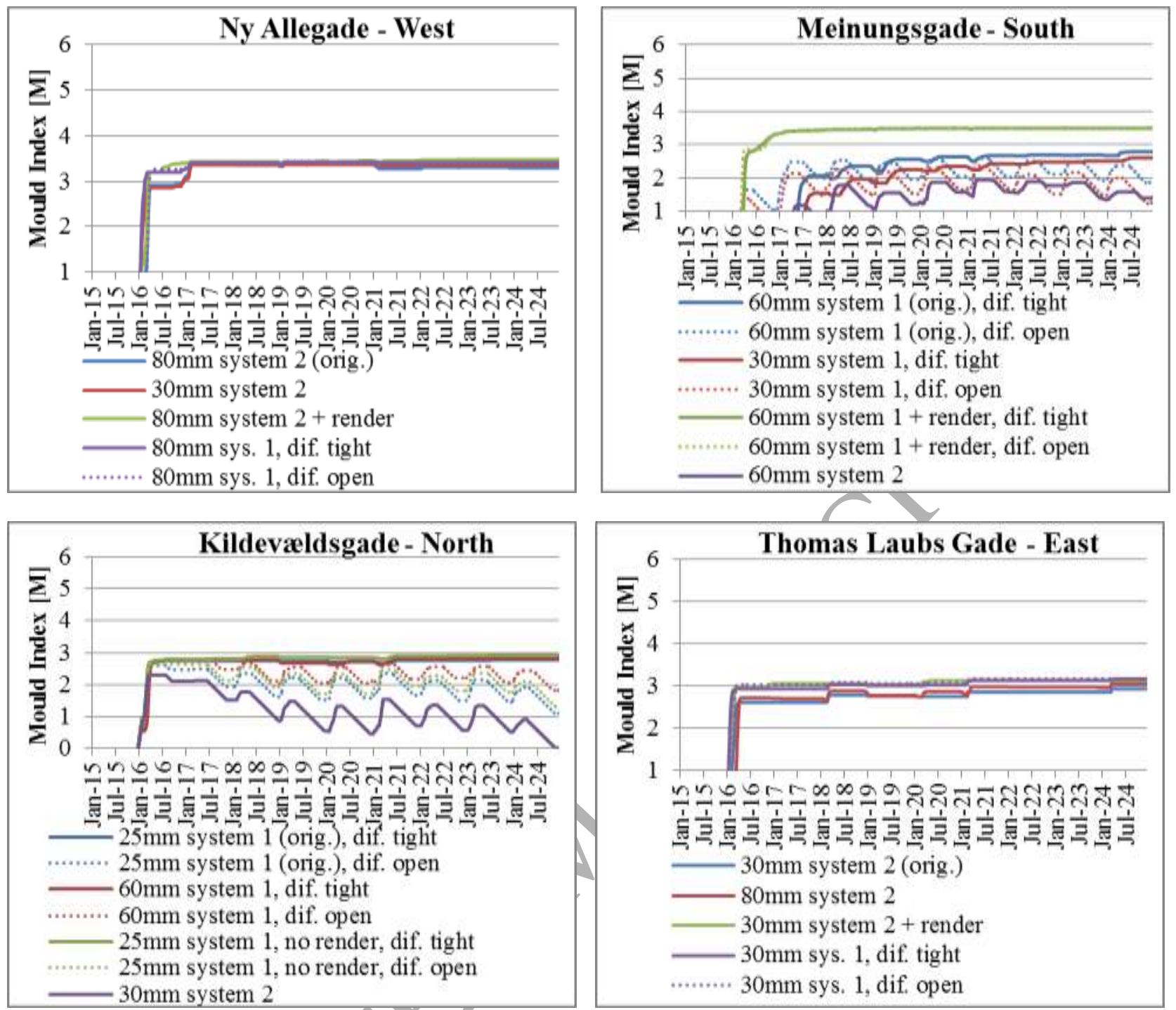

Figure 14: Generated Mould Indexes for simulated variations of insulation thickness, external surface and insulation system for the four cases.

The impact of the parameter variations on the hygrothermal performance of the studied cases is summarized in Table 6.

These observations can be summarized as follows: that increasing internal insulation thickness and choosing a vapour tight insulation system results in higher relative humidity in the interface between internal insulation and the original wall. Results from hygrothermal simulations however, should be considered cautiously; as seen they can present the relative effect of the various variations. 
Table 6: Observed changes in simulated hygrothermal conditions as a result of parameter variations.

\begin{tabular}{|c|c|c|c|}
\hline & Thickness & Paint + render & Material \\
\hline Ny Allegade & $\begin{array}{l}\text { Reduction of insulation } \\
\text { thickness from } 80 \mathrm{~mm} \text { to } 30 \mathrm{~mm} \\
\text { does not yield significant } \\
\text { changes in the relative humidity. }\end{array}$ & $\begin{array}{l}\text { Application of external render and } \\
\text { paint yields a continuous increase } \\
\text { in relative humidity, and no sign } \\
\text { of decline }\end{array}$ & $\begin{array}{l}\text { Application of } 80 \mathrm{~mm} \text { system } 1 \\
\text { instead of system } 2 \text { yields slightly } \\
\text { higher relative humidity and less } \\
\text { drying in summer periods }\end{array}$ \\
\hline Meinungsgade & $\begin{array}{l}\text { Reduction of insulation } \\
\text { thickness, } 60 \mathrm{~mm} \text { to } 30 \mathrm{~mm} \\
\text { yields relative humidities } \\
\text { reduced with up to } 5 \% \text {. }\end{array}$ & $\begin{array}{l}\text { Application of external render } \\
\text { increases the relative humidity, } \\
\text { and yields no indication of drying } \\
\text { in warmer periods. }\end{array}$ & $\begin{array}{l}\text { 60mm system } 2 \text { exhibits lower } \\
\text { relative humidity than } 60 \mathrm{~mm} \\
\text { system } 1 . \text { System } 2 \text { als } \varnothing \text { yields } \\
\text { more seasonal variation, however } \\
\text { with an opposite tendency than } \\
\text { system } 1 \text { where higher relative } \\
\text { humidities are found in summer, } \\
\text { system } 2 \text { yields higher relative } \\
\text { humidities during winter. This } \\
\text { indicates the diffusion of moist } \\
\text { warm air from the inside through } \\
\text { the wall during winter with system } \\
2 .\end{array}$ \\
\hline Kildevældsgade & $\begin{array}{l}\text { Increasing the insulation } \\
\text { thickness from } 25-60 \mathrm{~mm} \\
\text { yielded no significant influence } \\
\text { on relative humidity. }\end{array}$ & $\begin{array}{l}\text { Removing the external render did } \\
\text { not have a significant effect on the } \\
\text { relative humidity, but it increased } \\
\text { slightly. }\end{array}$ & $\begin{array}{l}\text { Replacing } 25 \mathrm{~mm} \text { of system } 1 \text { with } \\
30 \mathrm{~mm} \text { system } 2 \text { yielded reduced } \\
\text { relative humidity. System } 2 \text { also } \\
\text { yielded larger seasonal variation } \\
\text { with high relative humidity during } \\
\text { winter, which is the opposite } \\
\text { tendency of system } 1 .\end{array}$ \\
\hline Thomas Laubs Gade & $\begin{array}{l}\text { Increasing the insulation } \\
\text { thickness from } 30 \text { to } 80 \mathrm{~mm} \\
\text { yielded higher relative } \\
\text { humidities, especially in } \\
\text { summer. } 80 \mathrm{~mm} \text { system } 2 \text { in this } \\
\text { case seems to have less seasonal } \\
\text { variation, as less drying is } \\
\text { apparent during summer. }\end{array}$ & $\begin{array}{l}\text { Application of render on the } \\
\text { external surface increases the } \\
\text { relative humidity, and yields less } \\
\text { seasonal variation; hence less } \\
\text { possibility for drying during } \\
\text { summer. }\end{array}$ & $\begin{array}{l}\text { Substitution of system } 2 \text { with } \\
\text { system } 1 \text { causes the relative } \\
\text { humidity to increase with a few } \\
\text { percentages for all seasons. }\end{array}$ \\
\hline
\end{tabular}

\subsection{Discussion of the monitored and simulated results}

Results from in situ measurements show the tendency of a larger success rate in cases of insulation system 1 , whereas the simulations of the diffusion tight system 1 show the opposite tendency. These discrepancies can be explained by the way installation has been executed at the site, which does not result in a vapour tight system but instead allows vapour diffusion and perhaps also convection in air pockets behind the insulation system 1, as described in section 3.3 . Inclusion of a vapour barrier in the simulation therefore seems to have a negative effect in regards to interior insulation for the presented cases. The simulation results indicate that an insulation system, where the plates are not fully bonded to the walls, and yield some space for convection and/or vapour diffusion at the interface, results in the lowest risk for moisture damage. Simulations as well as in situ measurements do not indicate the capillary active effect of insulation 
system 2 being as efficient as intended. Again, this may be explained by the installation process, and the possibility of the insulation plates not being fully bonded and distributing moisture as intended. Capillary active systems are often promoted as being vapour open and able to avoid interstitial condensation due to the capillary forces and buffering in the material, however the calcium silicate channels in system 2 may not be sufficient for achieving the desired effect. The capillary absorption coefficient of system 2 and the associated glue mortar has been found to be very low [18] compared to other claimed capillary active insulation systems which impedes the redistribution of potential moisture from either driving rain or interstitial condensation. The capillary active system should be diffusion open for the allowance of redistribution of water vapour, for evaporation on the internal side, however system 2 , comprising mostly of vapour tight PUR, has a 2-3 times higher $S_{\mathrm{d} \text {,dry }}$ value, compared to other capillary active insulation systems [18]. A more capillary active material, such as pure calcium silicate, may also yield better hygrothermal results, but the thermal conductivity of such a product would be about $50 \%$ higher than that of system 2. In both cases of system 1 , Meinungsgade and Kildevældsgade, a $20 \mathrm{~cm}$ air gap has been left above the floor, as an intentional thermal bridge in an attempt to increase the temperature and drying potential at the beam ends. The gap seems to yield the desired effect, as the conditions behind the beam ends are not critical. Harrestrup et. al. [22] found through measurements and hygrothermal simulations, that internal insulation on northern-oriented façades could not be recommended as the lack of solar radiation yields little drying potential. On the other hand, the case at Kildevældsgade represents a northern oriented internally insulated façade that performs quite well. This case, however, also features external render and paint, which may act as a form of protection from external moisture sources. At Kildevældsgade a thin layer of insulation was applied and the simulation did show slightly increased risk of mould growth when either increasing the insulation thickness or removing the external render. Meinungsgade exhibits a significantly larger risk of mould growth with the inclusion of external render and paint. This may be explained by the orientation of the façade; south and southwest are the most exposed façades in regard to wind driven rain. An extra external layer of render with a higher water absorption coefficient may mean increased water uptake during rain spell, and decreased drying potential from the sun and the increased diffusion resistance. Klõšeiko et al. [13] tested several insulation systems on a northern oriented, externally rendered facade, and found that critical relative humidities after the installation of internal insulation were highest in the case of IQ-Therm, indicating the extended drying period for built in moisture, which may be the case for Ny Allegade and Thomas Laubs Gade. At Thomas Laubs Gade, there is an indication of slow reduction in the relative humidity at the interface. But this tendency is not apparent in Ny Allegade. It should be kept in mind, that some insulation materials, especially ones containing gas, have shown to have variable thermal conductivities, and also be dependent on 
temperature [33], why the hygrothermal simulations may be subjected to further errors than the various estimations made, and the theoretical U-value reductions presented may vary. However, as described above, the best hygrothermal performance, with regard to in-situ measurements, were found to be in the cases of insulation system 1 . This system has a lower thermal conductivity than system 2, and thus the theoretical energy savings are higher, despite lower thickness. In both cases of insulation system 1 , an intentional thermal bridge was incorporated at the floor, by means of a $20 \mathrm{~cm}$ uninsulated gap. The conditions in the beam ends were acceptable in these cases, indicating the effectiveness of the intentional thermal bridge. This was also demonstrated by Odgaard et. al. [34]. In regard to the in situ measurements, it should be noted, that during the long term measurement period, re-calibration of the sensors was not possible, and the results might drift to a little extent [35], however the results give clear indications of the actual hygrothermal conditions. Finally, the simulations indicate that there is no significant difference in the long-term performance between the two insulation systems, which to a greater extent depends on the external loads on the façade.

\section{Conclusion}

The study presents results from long-term measurements of four cases of solid historical masonry with internal insulation and predicted performance of them according to hygrothermal simulations. The cases vary in location, façade orientation, external surface, insulation thickness and insulation system/material. For the two cases of insulation system 2, the in situ measurements proved very high and unacceptable relative humidities. In Thomas Laubs Gade, where 30mm was applied, the relative humidity did show a tendency of decrease, which was not the case for Ny Allegade with $80 \mathrm{~mm}$, despite the longer time frame. Hygrothermal simulations also showed reduction in relative humidity with reduction of thickness. For insulation system 1, the in situ measurements in both cases presented acceptable hygrothermal conditions within the wall. The case with thicker insulation, and facing the most exposed orientation (south and southwest), Meinungsgade, showed a longer initial period for drying out of the wall post insulation. Kildevældsgade was found to be sufficiently dry 6 months post insulation, but this case also faces north (less exposed to wind driven rain), the surface is rendered and painted, and the insulation thickness is less. Hygrothermal simulations revealed a better performance, when air flow or convection on the inside was included, and unacceptable conditions for the vapour tight system. Hence, results from in-situ measurements and simulations showed opposite conclusions: while systems with vapour tight insulation and vapour barrier performed better than the system with calcium silicate channels according to the in situ measurements, the opposite was the case according to hygrothermal simulations. This discrepancy was explained by the method insulation systems are mounted in reality that allows vapour diffusion in the 
interface of insulation and the original wall. This indicates that the vapour barrier in reality doesn't contribute positively to the performance of the system. Hygrothermal simulations show that the inclusion of a vapour tight membrane increases the relative humidity and the risk of mould growth. Simulated parameter variations supported this observation: the more vapour open and the capillary active system, the better the performance, but this conclusion is highly dependent on other parameters, e.g. different external climatic loads on the façade. In addition, an increase in the insulation thickness seems to slightly increase the relative humidity and risk of mould growth. The study essentially enlightens the fact that all cases behave differently to parameter changes. Therefore, before application of internal insulation, the case should be carefully assessed with hygrothermal assessment methods, in order to find the most suitable solution with regard to both thermal and hygrothermal performance.

\section{Acknowledgements}

The presented work is a part of RIBuild project that has received funding from the European Union's Horizon 2020 research and innovation programme under grant agreement No 637268. The measurement data used for this study are a continuation of measurements performed for the EUDP project 2013-II: "Energy efficient comfort in older apartment blocks". The cases have been provided by Arup \& Hvidt (Meinungsgade), Klimakarré Østerbro (Kildevældsgade and Thomas Laubs Gade), and privately (Ny Allégade).

\section{References}

[1] J. Buzek, D. López Garrido, Directive 2010/31/EU of the European Parliament and of the Council of 19 May 2010 on the Eenergy Performance of Buildings, 2010. http://eur-lex.europa.eu/legalcontent/EN/ALL/?uri=CELEX:32010L0031.

[2] M. Economidou, J. Laustsen, P. Ruyssevelt, D. Staniaszek, Europe 'S Buildings Under the Microscope, 2011. http://bpie.eu/publication/europes-buildings-under-the-microscope/.

[3] C. Balocco, G. Grazzini, A. Cavalera, Transient analysis of an external building cladding, Energy Build. 40 (2008) 1273-1277. doi:10.1016/j.enbuild.2007.11.008.

[4] E. Kossecka, J. Kosny, Influence of insulation configuration on heating and cooling loads in a continuously used building, Energy Build. 34 (2002) 321-331. doi:10.1016/S0378-7788(01)00121-9.

[5] S.P. Bjarløv, G.R. Finken, T. Odgaard, Retrofit with interior insulation on solid masonry walls in cool 
temperate climates - An evaluation of the influence of interior insulation materials on moisture condition in the building envelope, Energy Procedia. 78 (2015) 1461-1466. doi:10.1016/j.egypro.2015.11.171.

[6] J. Munch-Andersen, SBi-anvisning 221: Efterisolering af etageboliger, 1., Statens Byggeforskningsinstitut, Hørsholm, 2008.

[7] E. Brandt, SBi-anvisning 224 Fugt i bygninger, 1., Statens Byggeforskningsinstitut, Hørsholm, 2009.

[8] J. Toman, A. Vimmrová, R. Černý, Long-term on-site assessment of hygrothermal performance of interior thermal insulation system without water vapour barrier, Energy Build. 41 (2009) 51-55. doi:10.1016/j.enbuild.2008.07.007.

[9] P. Mensinga, J. Straube, C. Schumacher, Assessing the freeze-thaw resistance of clay brick for interior insulation retrofit projects, in: 11th Int. Conf. Therm. Perform. Exter. Envel. Whole Build. Build. XI, 2010. doi:10.1081/E-EEE2-120046011.

[10] J. Zhao, J. Grunewald, U. Ruisinger, S. Feng, Evaluation of capillary-active mineral insulation systems for interior retrofit solution, Build. Environ. 115 (2017) 215-227. doi:10.1016/j.buildenv.2017.01.004.

[11] R. Walker, S. Pavía, Thermal performance of a selection of insulation materials suitable for historic buildings, Build. Environ. 94 (2015) 155-165. doi:10.1016/j.buildenv.2015.07.033.

[12] D.I. Kolaitis, E. Malliotakis, D.A. Kontogeorgos, I. Mandilaras, D.I. Katsourinis, M.A. Founti, Comparative assessment of internal and external thermal insulation systems for energy efficient retrofitting of residential buildings, Energy Build. Energy Build. 64 (2013) 123-131.

[13] P. Klõšeiko, E. Arumägi, T. Kalamees, Hygrothermal performance of internally insulated brick wall in cold climate: A case study in a historical school building, J. Build. Phys. (2014) 1744259114532609-. doi:10.1177/1744259114532609.

[14] J. Straube, C. Schumacher, Interior Insulation Retrofits of Load-Bearing Masonry Walls in Cold Climates, J. Green Build. 2 (2007) 42-50. doi:10.3992/jgb.2.2.42.

[15] E. Vereecken, L. Van Gelder, H. Janssen, S. Roels, Interior insulation for wall retrofitting - A probabilistic analysis of energy savings and hygrothermal risks, Energy Build. 89 (2015) 231-244. doi:10.1016/j.enbuild.2014.12.031.

[16] G.R. Finken, S.P. Bjarløv, R.H. Peuhkuri, Effect of façade impregnation on feasibility of capillary active thermal internal insulation for a historic dormitory - A hygrothermal simulation study, Constr. Build. Mater. 113 (2016) 202-214. doi:10.1016/j.conbuildmat.2016.03.019. 
[17] Z. Pavlík, R. Černý, Hygrothermal performance study of an innovative interior thermal insulation system, Appl. Therm. Eng. 29 (2009) 1941-1946. doi:10.1016/j.applthermaleng.2008.09.013.

[18] E. Vereecken, S. Roels, Capillary Active Interior Insulation Systems for Wall Retrofitting: A More Nuanced Story, Int. J. Archit. Herit. 10 (2016) 558-569. doi:10.1080/15583058.2015.1009575.

[19] T. Bunch-Nielsen, G. Christensen, Byg-Erfa Erfaringsblad (27) 051229 Uventilerede paralleltage med dampbremse af hygrodiode, (2005). https://byg-erfa.dk/uventilerede-hygrodiode.

[20] S. Kirkeskov Jensen, C. Rode, K. Kielsgaard Hansen, N.P. Kloch, Non-isothermal Laboratory Measurements of Moisture Profiles in Calcium Silicate for Interior Insulation Applications, in: 2. Int. Innendämmkongress, 2013: pp. $97-106$.

[21] P. Klõšeiko, E. Arumägi, T. Kalamees, Hygrothermal performance of internally insulated brick wall in a cold climate: field measurement and model calibration, in: Proc. 2nd Cent. Eur. Symp. Build. Phys., 2013. doi:10.1081/E-EEE2-120046011.

[22] M. Harrestrup, S. Svendsen, Internal insulation applied in heritage multi-storey buildings with wooden beams embedded in solid masonry brick façades, Build. Environ. 99 (2016) 59-72. doi:10.1016/j.buildenv.2016.01.019.

[23] A. Abdul Hamid, P. Wallentén, Hygrothermal assessment of internally added thermal insulation on external brick walls in Swedish multifamily buildings, Buíld. Environ. 123 (2017) 351-362. doi:10.1016/j.buildenv.2017.05,019.

[24] A. Nicolai, J. Grunewald, Delphin 5 User Manual and Program Reference, Program. (2006).

[25] T. Ojanen, R. Peuhkuri, Viitanen, Lähdesmäki, Vinha, Salminen, Classification of material sensitivity-new approach for mould growth modeling, in: 9th Nord. Symp. Build. Phys., 2011: pp. 867-874.

http://webhotel2.tut.fi/nsb2011/sites/webhotel2.tut.fi.nsb2011/files/b10_02_tuomo_ojanen_vtt_nordic_9th_clas sification_mould_growth_final2.pdf.

[26] A. Hukka, H. Viitanen, A mathematical model of mould growth on wooden material, Wood Sci. Technol. 33 (1999) 475-485. doi:10.1007/s002260050131.

[27] E. Vereecken, S. Roels, Review of mould prediction models and their influence on mould risk evaluation, Build. Environ. 51 (2012) 296-310. doi:10.1016/j.buildenv.2011.11.003.

[28] E. Vereecken, K. Vanoirbeek, S. Roels, Towards a more thoughtful use of mould prediction models: A critical view on experimental mould growth research, J. Build. Phys. 39 (2015) 102-123. 
doi:10.1177/1744259115588718.

[29] H. Viitanen, M. Krus, T. Ojanen, V. Eitner, D. Zirkelbach, Mold risk classification based on comparative evaluation of two established growth models, Energy Procedia. 78 (2015) 1425-1430. doi:10.1016/j.egypro.2015.11.165.

[30] Kingspan Insulation ApS, Produktoversigt Danmark Marts 2016 - Super Effektiv og Højtydende Isolering til Alle Formål, Roskilde, 2016. file:///C:/Users/camil/Downloads/Produktoversigt-Danmark-Marts-2016.pdf.

[31] EU, Climate for Culture, (2014). https://www.climateforculture.eu/.

[32] J. Straube, Simplified Prediction of Driving Rain on Buildings : ASHRAE 160P and WUFI 4.0, Build. Sci. Dig. (2010) 1-16. file://C:/Users/tekhan/Downloads/BSD-148_Simplified_Prediction_Driving_Rain.pdf.

[33] U. Berardi, M. Naldi, The impact of the temperature dependent thermal conductivity of insulating materials on the effective building envelope performance, Energy Build. 144 (2017) 262-275. doi:10.1016/j.enbuild.2017.03.052.

[34] T. Odgaard, S.P. Bjarløv, C. Rode, Influence of hydrophobation and deliberate thermal bridge on hygrothermal conditions of internally insulated historic solid masonry walls with built-in wood (Unpublished results/in press), Energy Build. (n.d.).

[35] S. Ahola, J. Lahdensivu, Long term monitoring of repaired external wall assembly, Energy Procedia. 0 (2017) 11-14. doi:10.1016/j.egypro.2017.09.635. 